\title{
Dynamic Characteristics Study with Multidegree-of-Freedom Coupling in TBM Cutterhead System Based on Complex Factors
}

\author{
Wei Sun, ${ }^{1}$ Jingxiu Ling, ${ }^{1}$ Junzhou Huo, ${ }^{1}$ Li Guo, ${ }^{1}$ Xu Zhang, ${ }^{1}$ and Liying Deng ${ }^{2}$ \\ ${ }^{1}$ School of Mechanical Engineering, Dalian University of Technology, Dalian 116024, China \\ ${ }^{2}$ Northern Heavy Industry Group Ltd., Shenyang 110141, China \\ Correspondence should be addressed to Junzhou Huo; huojunzhou@dlut.edu.cn
}

Received 8 October 2013; Revised 18 November 2013; Accepted 18 November 2013

Academic Editor: Rongni Yang

Copyright (c) 2013 Wei Sun et al. This is an open access article distributed under the Creative Commons Attribution License, which permits unrestricted use, distribution, and reproduction in any medium, provided the original work is properly cited.

\begin{abstract}
A multidegree-of-freedom coupling dynamic model, which contains a joint cutterhead, an inner ring gear, a support shield body, and pinions, is established, considering the external stochastic excitations, time-varying meshing stiffness, transmission errors, clearance, and so forth. Based on the parameters of an actual project and the strong impact of external excitations, the modal properties and dynamic responses are analyzed, and the cutterhead joint surface loads are obtained and treated by rain flow count. Numerical results indicate that the low natural frequencies are $57 \mathrm{~Hz}$ and $61 \mathrm{~Hz}$, and natural vibration modes are pinionsmotors rotational mode and translational-overturning coupled mode of cutterhead with inner ring gear correspondingly. Besides, the axial and radial amplitude of dynamic responses are $0.55 \mathrm{~mm}$ and $0.25 \mathrm{~mm}$, respectively. The frequencies of radial, torsional, and overturning vibrations are predominantly concentrated in $112 \mathrm{~Hz}$ and $120 \mathrm{~Hz}$, which indicates that the vibration responses of cutterhead are mainly affected by the external excitations. Finally, as the rain-flow counting results have shown, the standard deviation of the cutterhead joint surface loads in each direction increases by 12-15 times, compared with that of the external excitations; therefore inertia effect should be considered in cutterhead design. The proposed research lays a foundation for dynamic performance optimization and fatigue crack growth life assessment of cutterhead structure.
\end{abstract}

\section{Introduction}

As a key component of the full face rock tunnel boring machine (TBM), the cutterhead plays the functions of crushing rock, stabilizing excavated opening, and so on, which affects the boring performance and efficiency of the whole machine [1]. Due to complicated geological conditions and variable tunneling parameters, cutterhead endures multipoint random impact loads, in many projects, for example, the Qinling tunnel, Dahuofang tunnel, and Zhongtianshan tunnel [2-4]. As a result, some engineering faults may appear, such as severe vibration, abnormal wears of cutting tools, cracking of cutterhead panel, and the seal failure of main bearing, which put forward high design requirements for structural strength, reliability, and fatigue life of cutterhead. Therefore, aiming at absorbance of dynamic impact loads, high reliability, high fatigue life, and superior static and dynamic characteristics, the research on coupled nonlinearity dynamical characteristics of TBM cutterhead system with random impact loads provides an important theoretical value and practical significance.

For a long time, a great number of studies about the TBM cutterhead system design have been carried out. Samuel and Seow [5] studied the variations of cutter forces during field testing, and the instantaneous forces are compared to global machine performance. Zhang et al. [6] proposed the testing methods using the results, which are obtained in the measured cutter forces on a boring machine during field boring in a hard rock laboratory. According to Rostami [7], the distribution of cutters is critical to balance performance of cutterhead, and the methods of cutterhead system design for the hard rock TBM were studied based on different performance factors. A model of the specific energy $[8,9]$ was created for evaluating the energy consumption of tunnel machine. Then the model was conducted using the testing data from a subway project, so as to provide optimal ranges of the cutting depth per revolution. Furthermore, Xia et al. [10, 11] used the discrete element method to study the influence of 
cutterhead performance under various geological conditions and cutter spaces, and the results were compared with a cutting test. Similar works present as follows. Sun et al. [1215] studied the simulation process of rock fragmentation with multicutters and space design. Moreover, based on the genetic algorithm and collaborative evolutionary, the method of disc cutters' plane layout design was proposed, as well as the optimal design for master parameter of cutterhead structure and support ribs were processed. In addition, a theoretical dynamic model of shield TBM has been established by Zhang [16], considering the interactions among the redundantly driven revolving system, hydraulic propulsion system, shield body, and geologic condition, to study the dynamic characteristics of revolving system under comprehensive geological conditions. Some related literature on multidegree-of-freedom coupling dynamic model have been published recently. Sakanushi et al. [17] and Yamada et al. [18] proposed the control characteristics and a design procedure of a two-degree-of-freedom simple repetitive control system which can specify the input-output characteristic and the disturbance attenuation characteristic separately, and a numerical example and an application in motors were presented to illustrate the effectiveness, which showed that the control system was expected to be used in practical applications. A six-degree-of-freedom fully-coupled plant model used in underwater vehicles was reported in [19], and the comparative experimental evaluations were estimated experimentally from data obtained in free-motion vehicle trials, which might be able to predict the performance of underwater vehicles.

As mentioned above, scholars have studied rock fragmentation mechanism, force models of disc cutters, stochastic loads of excavation, and disc cutters' plane layout about the TBM cutterhead system, by using the methods of similar model experiment, numerical simulation, and field test. In addition, many design methods and research achievements about multidegree-of-freedom coupling dynamic model have been obtained, which are of valuable reference to our study. However, the problem of vibration in split type of cutterhead with heavy random loads has not been previously performed. Moreover, the dynamic model in [16] did not consider the radial freedom of the cutterhead because of the small loads in the shield TBM system, which cannot be employed in the hard rock TBM system. The design methods in TBM cutterhead were presented in [12-15] to optimize the structure parameter, but the cutters' loads were static nominal load, ignoring the dynamic characteristic. These former models about cutterhead system may not be close to the actual conditions. Therefore, for the first time, this paper studies the dynamic characteristics of split-cutterhead system with multidegree-of-freedom coupling, comprehensively considering the time-varying external excitations, time-varying meshing stiffness, transmission errors, clearance, and bearing stiffness. Compared with conventional design methods and models, the proposed research is more effective to solve the complex project problems, which provides an effective foundation for dynamic performance optimization and fatigue crack propagation life assessment of cutterhead structure.

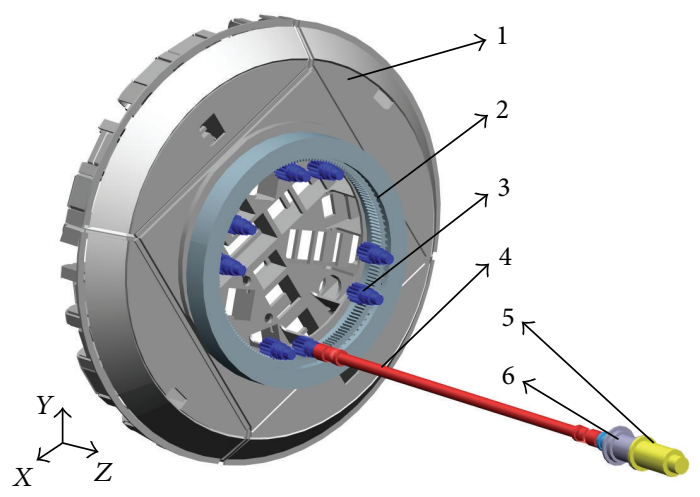

Figure 1: Components of TBM cutterhead system. 1: Cutterhead piece. 2: Main bearing. 3: Pinion. 4: Coupling. 5: Motor. 6: Reducer.

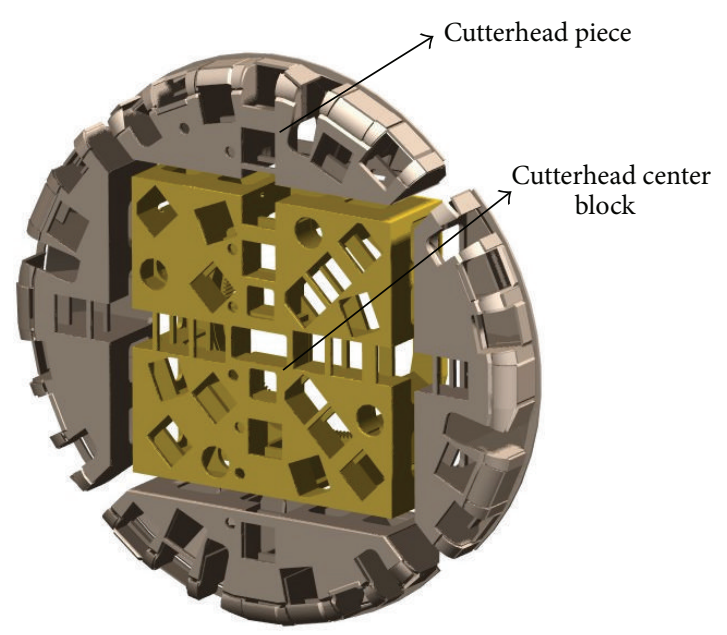

FIgURE 2: The structure of TBM split cutterhead.

\section{The Split-Cutterhead System of Coupled Dynamics Model Influenced by Complicated Factors}

In the TBM cutterhead system, the multiple pinions are driven by variable-frequency motors via planetary gear reducers and couplings. Then, the pinions drive an inner ring gear clockwise by redundant control, and the inner ring gear and flange are fixed with bolts, so as to drive the cutterhead. The TBM cutterhead system with various components is shown in Figure 1; here, we just present only one motor driving system. Meanwhile, the structure of TBM split-cutterhead is shown in Figure 2.

In this paper, a dynamic mathematic model of TBM cutterhead system is established by using lumped-parameter method, which is shown in Figure 3, where $k_{m p Q}$ and $k_{r L Q}$ are the torsional stiffness of gear shaft connections and cutterhead shaft connection, respectively, $k_{e q y}, k_{e q L}, k_{e q r}$, $k_{\text {eqz }}, k_{\text {eqd }}$, and $k_{\text {eqdz }}$ are the equivalent radial stiffness and axial stiffness of cutterhead, inner ring gear, and support shield body, respectively, $k_{e q p}$ and $k_{(t)}$ are the support equivalent stiffness of pinions and time-varying meshing 

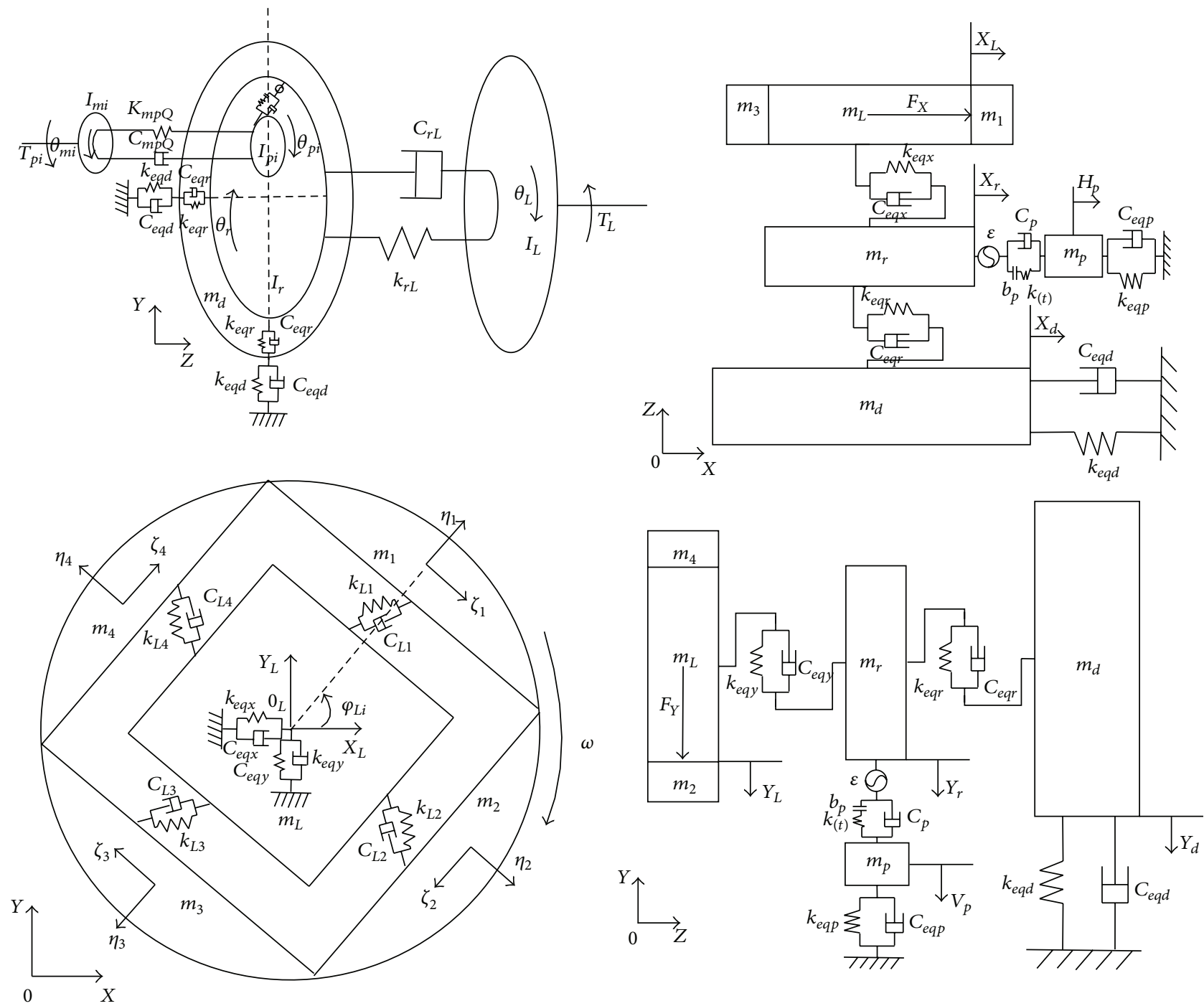

(a) Bend-torsion coupled dynamic model of cutterhead system

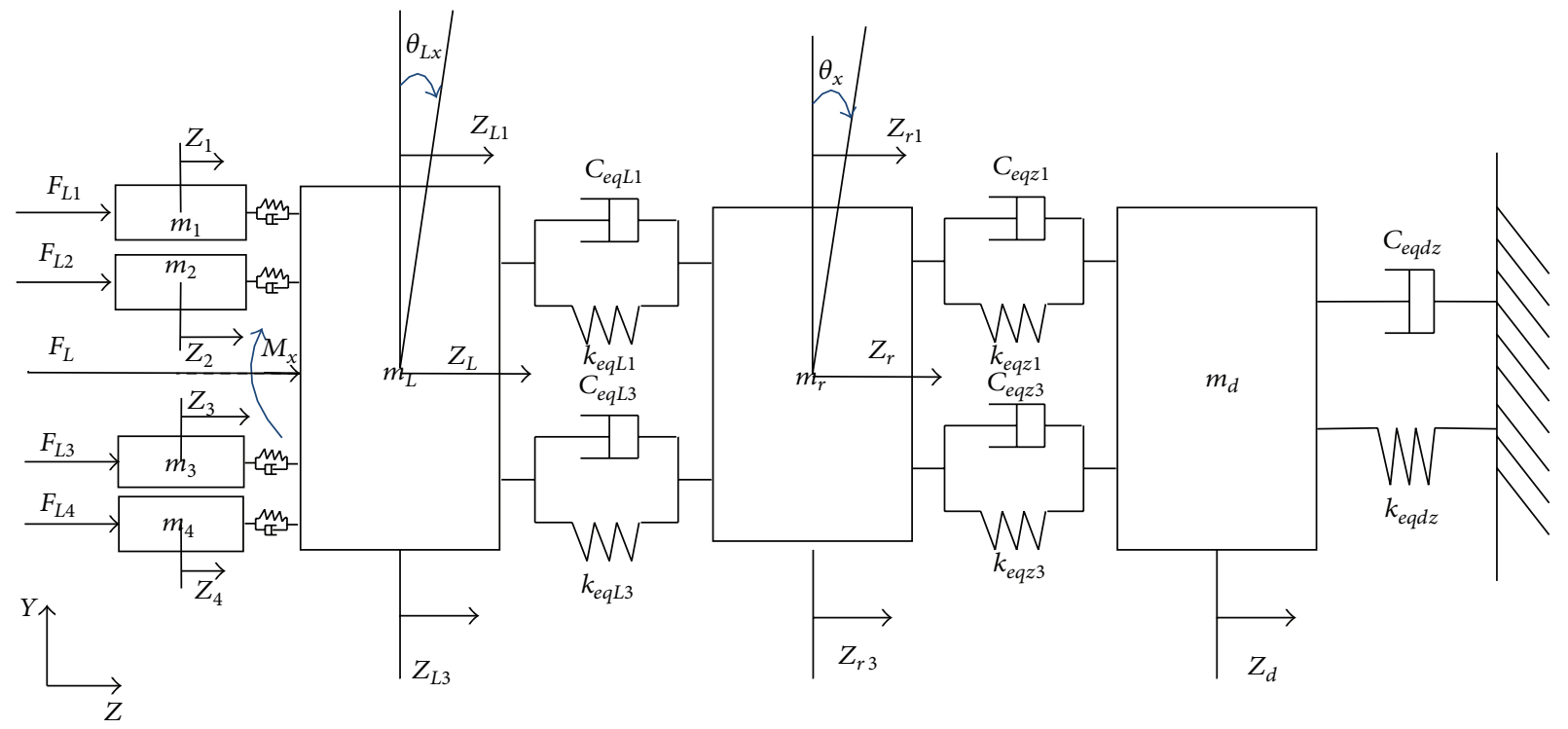

(b) Torsion-axial coupled dynamic model of cutterhead system

Figure 3: Continued. 


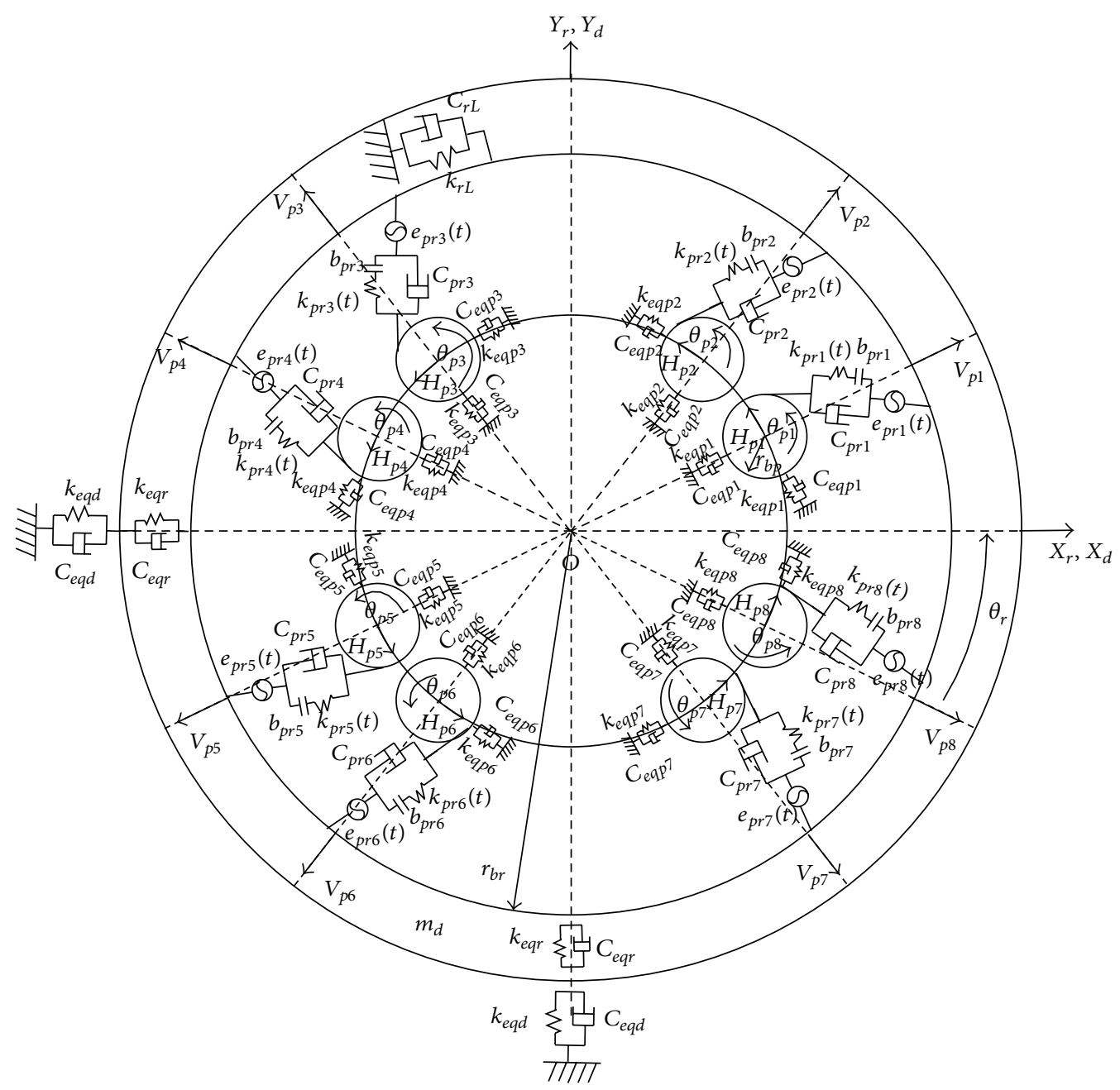

(c) Internal meshing dynamic model of cutterhead system

FIGURE 3: Multidegree-of-freedom coupling dynamic model of TBM cutterhead system.

stiffness between inner ring gear and pinions, respectively, and $k_{L \zeta i}, k_{L \eta i}$, and $k_{L i}$ are the equivalent tangential stiffness, radial stiffness, and axial stiffness of each cutterhead piece, respectively. $C_{x x x}(x x x$ denotes the subscript) is the damping coefficient of corresponding stiffness. $T_{p i}, T_{L}, F_{X}, F_{Y}, F_{L}, M_{X}$, and $F_{L i}$ represent the input torque, load torque, lateral force, longitudinal force, and axial thrust, transverse overturning moment of cutterhead center block, as well as axial force of each cutterhead piece, respectively. The backlash between the inner ring gear and each pinion is expressed by $b_{p}$ and meshing errors are expressed by $\varepsilon$. Besides, $r_{b r}$ and $r_{b p}$, respectively, denote the base circle radius of inner ring gear and pinions.

In the dynamic model of cutterhead system abovementioned, the moving coordinate systems are used for convenient modeling. The coordinates are illustrated in Figure 3, where $X, Y$, and $Z$, respectively, denote horizontal direction, vertical direction, and tunneling direction, and cutterhead, inner ring gear and support shield body are in this coordinate. Additionally, $\zeta$ and $\eta$ are the radial and tangential directions of cutterhead pieces, which are rotating with cutterhead. Also, $H_{p}$ and $V_{p}$ are the radial and tangential directions of pinions. We use various subscripts for the purpose of distinguishing conveniently. The cutterhead pieces are specified by the subscript of $i$, and cutterhead center block, inner ring gear, and support shield body are $L, r$, and $d$, respectively, while pinions and motors are $p$ and $m$.

The system in Figure 3 has $(27+4 N)$ degree of freedoms, where $N$ is the number of pinions. The generalized vibration displacement is $X=\left(\zeta_{i}, \eta_{i}, Z_{i}, X_{L}, Y_{L}, Z_{L}, \theta_{L x}, \theta_{L y}\right.$, $\left.\theta_{L}, X_{r}, Y_{r}, Z_{r}, \theta_{x}, \theta_{y}, \theta_{r}, X_{d}, Y_{d}, Z_{d}, H_{p j}, V_{p j}, \theta_{p j}, \theta_{m j}\right)^{T}$, where $\zeta_{i}, \eta_{i}$, and $Z_{i}$ are the translational vibration displacements of each cutterhead piece. $X_{L}, Y_{L}$, and $Z_{L}$ are the translational vibration displacements, $\theta_{L x}$ and $\theta_{L y}$ are the bending vibration displacements around $X$ and $Y$ directions, and $\theta_{L}$ is the torsional vibration displacement in center block. $X_{r}, Y_{r}, Z_{r}$, $\theta_{x}, \theta_{y}$, and $\theta_{r}$ are corresponding vibration displacements of the inner ring gear. $X_{d}, Y_{d}$, and $Z_{d}$ are the translational vibration displacements of the support shield body. $H_{p j}$ and $V_{p j}$ are the transverse and longitudinal vibration displacements 
of the mass center of each pinion, respectively. $\theta_{p j}$ is the torsional vibration displacements of each pinion and $\theta_{m j}$ is the torsional vibration displacements of each motor.

Because of the low speed of cutterhead, Coriolis accelerations and centripetal accelerations are ignored in published models. The differential equations of each component are as follows, based on the Lagrange's equation.

(1) For motors,

$$
I_{m j} \ddot{\theta}_{m j}+C_{m p Q}\left(\dot{\theta}_{m j}-\dot{\theta}_{p j}\right)+k_{m p Q}\left(\theta_{m j}-\theta_{p j}\right)=T_{p j} .
$$

(2) For pinions,

$$
\begin{gathered}
I_{p j} \ddot{\theta}_{p j}+\left(F_{p r j}+D_{p r j}\right) r_{b p}+C_{m p Q}\left(\dot{\theta}_{p j}-\dot{\theta}_{m j}\right) \\
+k_{m p Q}\left(\theta_{p j}-\theta_{m j}\right)=0, \\
m_{p j} \ddot{H}_{p j}+\left(F_{p r j}+D_{p r j}\right) \cos \alpha+C_{e q p j} \dot{H}_{p j}+k_{e q p j} H_{p j}=0, \\
m_{p j} \ddot{V}_{p j}+\left(F_{p r j}+D_{p r j}\right) \sin \alpha+C_{e q p j} \dot{V}_{p j}+k_{e q p j} V_{p j}=0 .
\end{gathered}
$$

Thus, $x_{p r j}$ is the relative dynamic displacement between each pinion and the inner gear ring along with the internal meshing line is expressed as

$$
\begin{aligned}
x_{p r j}= & r_{b p} \theta_{p j}-r_{b r} \theta_{r}+V_{p j} \sin \alpha+H_{p j} \cos \alpha \\
& +X_{r} \sin \left(\alpha+\varphi_{j}\right)-Y_{r} \cos \left(\alpha+\varphi_{j}\right)-\varepsilon_{p r j}(t),
\end{aligned}
$$

where $\varepsilon_{p r j}(t)(j=1-N)$ is the system error excitations, shown in part $2, \alpha$ is meshing angle, and $\varphi_{j}$ is the azimuth angle of each pinion, shown in Figure 2(c).

Then, the dynamic meshing loads can be calculated as

$$
F_{p r j}=k_{p r j}(t) \cdot f\left(x_{p r j}, b_{p r j}\right),
$$

where $b_{p r j}$ is half of the backlash among inner ring gear and pinions, $k_{p r j}(t)$ is time-varying meshing stiffness, and $f(x, b)$ is the nonlinear function, which can be expressed as

$$
f(x, b)= \begin{cases}x-b, & x>b \\ 0, & -b \leq x \leq b \\ x+b, & x<-b\end{cases}
$$

Similarly, the forces of meshing damping are expressed as

$$
D_{p r j}=C_{p r j} \cdot \dot{x}_{p r j} .
$$

(3) For inner ring gear

$$
\begin{aligned}
m_{r} \ddot{X}_{r} & +\sum_{j=1}^{N}\left(F_{p r j}+D_{p r j}\right) \sin \left(\varphi_{j}+\alpha\right)+C_{e q r}\left(\dot{X}_{r}-\dot{X}_{d}\right) \\
& +C_{e q x}\left(\dot{X}_{r}-\dot{X}_{L}\right)+k_{e q r}\left(X_{r}-X_{d}\right) \\
& +k_{e q x}\left(X_{r}-X_{L}\right)=0
\end{aligned}
$$

$$
\begin{gathered}
m_{r} \ddot{Y}_{r}-\sum_{j=1}^{N}\left(F_{p r j}+D_{p r j}\right) \cos \left(\varphi_{j}+\alpha\right)+C_{e q r}\left(\dot{Y}_{r}-\dot{Y}_{d}\right) \\
+C_{e q y}\left(\dot{Y}_{r}-\dot{Y}_{L}\right)+k_{e q r}\left(Y_{r}-Y_{d}\right) \\
+k_{e q y}\left(Y_{r}-Y_{L}\right)=0, \\
m_{r} \ddot{Z}_{r}+\sum_{i=1}^{4}\left[C_{e q L i}\left(\dot{Z}_{r i}-\dot{Z}_{L i}\right)+C_{e q z i}\left(\dot{Z}_{r i}-\dot{Z}_{d}\right)\right. \\
\left.+k_{e q L i}\left(Z_{r i}-Z_{L i}\right)+k_{e q z i}\left(Z_{r i}-Z_{d}\right)\right]=0, \\
I_{r x} \ddot{\theta}_{x}+r_{r}\left[C_{e q L 1}\left(\dot{Z}_{r 1}-\dot{Z}_{L 1}\right)-C_{e q L 3}\left(\dot{Z}_{r 3}-\dot{Z}_{L 3}\right)\right. \\
\left.+C_{e q z 1}\left(\dot{Z}_{r 1}-\dot{Z}_{d}\right)-C_{e q z 3}\left(\dot{Z}_{r 3}-\dot{Z}_{d}\right)\right] \\
+r_{r}\left[k_{e q L 1}\left(Z_{r 1}-Z_{L 1}\right)-k_{e q L 3}\left(Z_{r 3}-Z_{L 3}\right)\right. \\
\left.+k_{e q z 1}\left(Z_{r 1}-Z_{d}\right)-k_{e q z 3}\left(Z_{r 3}-Z_{d}\right)\right]=0, \\
I_{r y} \ddot{\theta}_{y}+r_{r}\left[C_{e q L 2}\left(\dot{Z}_{r 2}-\dot{Z}_{L 3}\right)-C_{e q L 4}\left(\dot{Z}_{r 4}-\dot{Z}_{L 4}\right)\right. \\
\left.+C_{e q z 2}\left(\dot{Z}_{r 2}-\dot{Z}_{d}\right)-C_{e q z 4}\left(\dot{Z}_{r 4}-\dot{Z}_{d}\right)\right] \\
+r_{r}\left[k_{e q L 2}\left(Z_{r 2}-Z_{L 2}\right)-k_{e q L 4}\left(Z_{r 4}-Z_{L 4}\right)\right. \\
\left.+k_{e q z 2}\left(Z_{r 2}-Z_{d}\right)-k_{e q z 4}\left(Z_{r 4}-Z_{d}\right)\right]=0, \\
I_{r} \ddot{\theta}_{r}-\sum_{j=1}^{N}\left(F_{p r j}+D_{p r j}\right) r_{b r}+C_{r L Q}\left(\dot{\theta}_{r}-\dot{\theta}_{L}\right) \\
+k_{r L Q}\left(\theta_{r}-\theta_{L}\right)=0 .
\end{gathered}
$$

(4) For cutterhead center block:

$$
\begin{gathered}
m_{L} \ddot{X}_{L}-\sum_{i=1}^{4}\left[\left(k_{L \zeta i} \delta_{1 \zeta i}+C_{L \zeta i} \dot{\delta}_{L \zeta i}\right) \sin \left(\omega t+\varphi_{i}\right)\right. \\
\left.+\left(k_{L \eta i} \delta_{L \eta i}+C_{L \eta i} \dot{\delta}_{L \eta i}\right) \cos \left(\omega t+\varphi_{i}\right)\right] \\
+C_{e q x}\left(\dot{X}_{L}-\dot{X}_{r}\right)+k_{e q x}\left(X_{L}-X_{r}\right)=F_{X}, \\
m_{L} \ddot{Y}_{L}+\sum_{i=1}^{4}\left[\left(k_{L \zeta i} \delta_{1 \zeta i}+C_{L \zeta i} \dot{\delta}_{1 \zeta i}\right) \cos \left(\omega t+\varphi_{i}\right)\right. \\
\left.-\left(k_{L \eta i} \delta_{1 \eta i}+C_{L \eta i} \dot{\delta}_{1 \eta i}\right) \sin \left(\omega t+\varphi_{i}\right)\right] \\
+C_{e q y}\left(\dot{Y}_{L}-\dot{Y}_{r}\right)+k_{e q y}\left(Y_{L}-Y_{r}\right)=F_{Y}, \\
m_{L} \ddot{Z}_{L}+\sum_{i=1}^{4}\left[C_{L i}\left(\dot{Z}_{L i}-\dot{Z}_{i}\right)+k_{L i}\left(Z_{L i}-Z_{i}\right)\right. \\
\left.+C_{e q L i}\left(\dot{Z}_{L i}-\dot{Z}_{r i}\right)+k_{e q L i}\left(Z_{L i}-Z_{r i}\right)\right]=F_{L}, \\
I_{L x} \ddot{\theta}_{L x}+a_{L}\left[C_{L 1}\left(\dot{Z}_{L 1}-\dot{Z}_{1}\right)-C_{L 3}\left(\dot{Z}_{L 3}-\dot{Z}_{3}\right)\right. \\
\left.+k_{L 1}\left(Z_{L 1}-Z_{1}\right)-k_{L 3}\left(Z_{L 3}-Z_{3}\right)\right]
\end{gathered}
$$




$$
\begin{gathered}
+r_{r}\left[C_{e q L 1}\left(\dot{Z}_{L 1}-\dot{Z}_{r 1}\right)-C_{e q L 3}\left(\dot{Z}_{L 3}-\dot{Z}_{r 3}\right)\right. \\
\left.+k_{e q L 1}\left(Z_{L 1}-Z_{r 1}\right)-k_{e q L 3}\left(Z_{L 3}-Z_{r 3}\right)\right]=M_{X}, \\
I_{L y} \ddot{\theta}_{L y}+a_{L}\left[C_{L 2}\left(\dot{Z}_{L 2}-\dot{Z}_{2}\right)-C_{L 4}\left(\dot{Z}_{L 4}-\dot{Z}_{4}\right)\right. \\
\left.+k_{L 2}\left(Z_{L 2}-Z_{2}\right)-k_{L 4}\left(Z_{L 4}-Z_{4}\right)\right] \\
+r_{r}\left[C_{e q L 2}\left(\dot{Z}_{L 2}-\dot{Z}_{r 2}\right)-C_{e q L 4}\left(\dot{Z}_{L 4}-\dot{Z}_{r 4}\right)\right. \\
\left.+k_{e q L 2}\left(Z_{L 2}-Z_{r 2}\right)-k_{e q L 4}\left(Z_{L 4}-Z_{r 4}\right)\right]=M_{Y}, \\
I_{L} \ddot{\theta}_{L}+C_{r L Q}\left(\dot{\theta}_{L}-\dot{\theta}_{r}\right)+k_{r L Q}\left(\theta_{L}-\theta_{r}\right)=-T_{L} .
\end{gathered}
$$

(5) For support shield body,

$$
\begin{aligned}
m_{d} \ddot{X}_{d} & +C_{e q r}\left(\dot{X}_{d}-\dot{X}_{r}\right)+C_{e q d} \dot{X}_{d} \\
& +k_{e q r}\left(X_{d}-X_{r}\right)+k_{e q d} X_{d}=0, \\
m_{d} \ddot{Y}_{d} & +C_{e q r}\left(\dot{Y}_{d}-\dot{Y}_{r}\right)+C_{e q d} \dot{Y}_{d} \\
& +k_{e q r}\left(Y_{d}-Y_{r}\right)+k_{e q d} Y_{d}=0, \\
m_{d} \ddot{Z}_{d} & +C_{e q z 1}\left(\dot{Z}_{d}-\dot{Z}_{r 1}\right)+C_{e q z 2}\left(\dot{Z}_{d}-\dot{Z}_{r 2}\right) \\
& +C_{e q z 3}\left(\dot{Z}_{d}-\dot{Z}_{r 3}\right)+C_{e q z 4}\left(\dot{Z}_{d}-\dot{Z}_{r 4}\right) \\
& +C_{e q d z} \dot{Z}_{d}+k_{e q z 1}\left(Z_{d}-Z_{r 1}\right) \\
& +k_{e q z 2}\left(Z_{d}-Z_{r 2}\right)+k_{e q z 3}\left(Z_{d}-Z_{r 3}\right) \\
& +k_{e q z 4}\left(Z_{d}-Z_{r 4}\right)+k_{e q d z} Z_{d}=0 .
\end{aligned}
$$

(6) For cutterhead pieces,

$$
\begin{gathered}
m_{i} \ddot{\zeta}_{i}+k_{L \zeta i} \delta_{L \zeta i}+C_{L \zeta i} \dot{\delta}_{L \zeta i}=F_{\zeta i}, \\
m_{i} \ddot{\eta}_{i}+k_{L \eta i} \delta_{L \eta i}+C_{L \eta i} \dot{\delta}_{L \eta i}=F_{\eta i}, \\
m_{i} \ddot{Z}_{i}+k_{L i}\left(Z_{i}-Z_{L i}\right)+C_{L i}\left(\dot{Z}_{i}-\dot{Z}_{L i}\right)=F_{L i},
\end{gathered}
$$

where $F_{\zeta i}, F_{\eta i}$, and $F_{L i}$ are the tangential force, normal force, and axial force of each cutterhead piece, respectively.

The $\delta_{L \zeta i}$ and $\delta_{L \eta i}(i=1-4)$ in (10) are the tangential and radial relative deformations between each cutterhead piece and central block, expressed as follows:

$$
\begin{aligned}
& \delta_{L \zeta i}=\zeta_{i}-X_{L} \sin \varphi_{i}+Y_{L} \cos \varphi_{i}, \\
& \delta_{L \eta i}=\eta_{i}-X_{L} \cos \varphi_{i}-Y_{L} \sin \varphi_{i},
\end{aligned}
$$

where $\varphi_{i}$ is the azimuth angle of each cutterhead piece and four pieces are evenly distributed, $\varphi_{i}=\pi(i-1) / 2(i=1-4)$.

As discussed above, assembling the system equations in matrix form yields

$$
M \ddot{X}+C \dot{X}+K X=F,
$$

where $M$ is the mass matrix, $C$ and $K$, respectively, represent the damping matrix and stiffness matrix, and $F$ is the incentive force vector.

\section{Dynamic Excitations of TBM Cutterhead System}

There are two types of excitations in the dynamic model, which are external and internal excitations, influencing the dynamic characteristics of the cutterhead system. The external excitations depend on the time variability of the parameters of disc cutters' layout, geological conditions, tunneling parameters, and so forth. Meanwhile, the internal excitations are affected by the time-varying meshing stiffness, comprehensive accumulated errors, bearing stiffness, and so on.

3.1. External Excitations of TBM Cutterhead System. A 3D simulation model with multicutters is established, under typical geological conditions, based on the procedure of LSDYNA, due to complicated geological environments. Then, the dynamic loads between disc cutters and surrounding rock are obtained and modified reference to the field data $[5,6]$. Consequently, the total loads of the TBM cutterhead system are calculated by summing the individual force contributions of each cutter, which can be provided to external excitations of the dynamic model.

Theoretically speaking, the disc cutters suffer normal forces $F_{v}$, tangential forces $F_{r}$, and side forces $F_{s}$ when the cutterhead turns, as shown in Figure 4, where $\rho$ is the radius from the center of the cutterhead, $\theta$ is the position angle of the cutter, and $\beta$ is the tilt angle of the gauge cutter. For the convenience of loads calculation, the assumptions are formulated as follows.

(i) The total loads of cutterhead equal to the resultant force of each disc cutter, ignoring the losses in transfer process.

(ii) Considering the complexity of actual rock breaking loads, the mean normal force is equal to nominal load of the disc cutter, and it is 0.15 times the mean tangential force and 0.1 times the mean side force $[5,6]$.

Deduced the relationship between the loads of cutterhead and cutters, the formulae of loads in each cutterhead piece are presented by the following expressions.

(1) Axial Forces. The axial forces are equal to the resultant force in $Z$ direction of each cutter, which can be expressed as

$$
F_{L}=\sum_{i=1}^{n} F_{v i}+\sum_{j=1}^{m} F_{v j}+\sum_{k=1}^{p}\left(F_{v k} \cos \beta_{k}+F_{s k} \sin \beta_{k}\right),
$$

where $F_{v t}(t=i, j, k)$ are the normal force of the center cutter, normal cutter, and gauge cutter, respectively, $F_{s k}$ is the side force of the $k$ th gauge cutter, $n, m$, and $p$ are the number of the center cutter, normal cutter, and gauge cutter, respectively, and $\beta_{k}$ is the tilt angle of the $k$ th gauge cutter. 


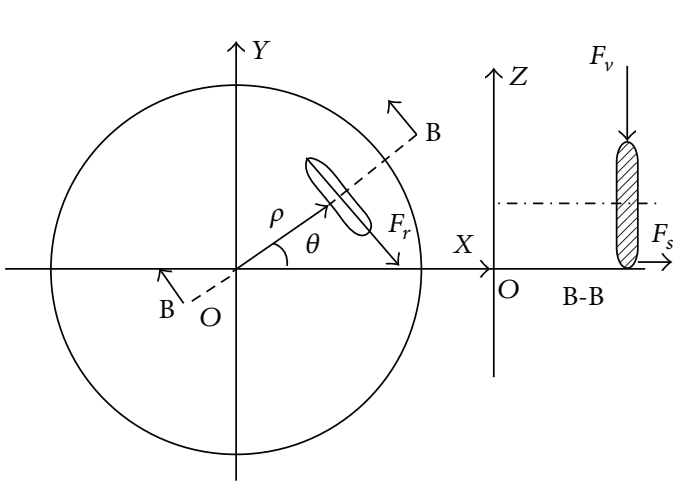

(a) Normal cutters

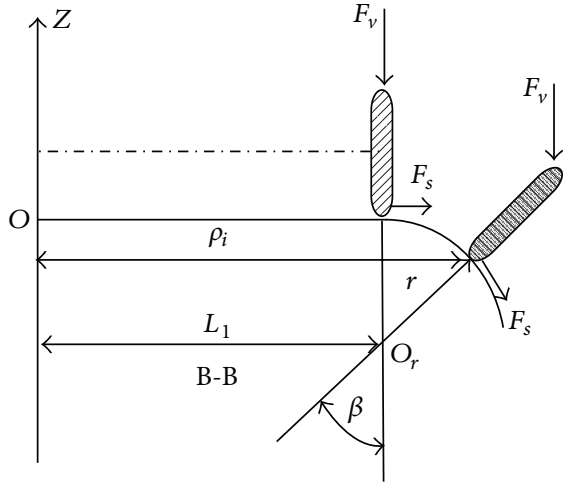

(b) Gauge cutters

FIGURE 4: Forces acting on a normal cutter and a gauge cutter [14].

Also, $F_{L i}$ can be calculated by (13), just with different number of disc cutters.

(2) Radial Forces. The radial forces can be decomposed into lateral force $F_{X}$ and longitudinal force $F_{Y}$ as

$$
\begin{aligned}
& F_{X}=F_{v x \Sigma}+F_{r x \Sigma}+F_{s x \Sigma}, \\
& F_{Y}=F_{v y \Sigma}+F_{r y \Sigma}+F_{s y \Sigma},
\end{aligned}
$$

where $F_{v x \Sigma}, F_{r x \Sigma}$, and $F_{s x \Sigma}$, respectively, represent the resultant force of normal forces, tangential forces, and side forces in $X$ direction, and the resultant forces in $Y$ direction are $F_{v y \Sigma}$, $F_{r y \Sigma}$, and $F_{s y \Sigma}$, correspondingly.

In the same way, $F_{\zeta i}$ and $F_{\eta i}$ are calculated by (14).

(3) Overturning Moments. Similarly, the overturning moments can also be decomposed into two directions, which load on the central block. Consider

$$
\begin{aligned}
& M_{X}=\sum_{i=1}^{n} F_{v i} l_{i x}+\sum_{j=1}^{m} F_{v j} l_{j x}, \\
& M_{Y}=\sum_{i=1}^{n} F_{v i} l_{i y}+\sum_{j=1}^{m} F_{v j} l_{j y},
\end{aligned}
$$

where $l_{t x}$ and $l_{t y}(t=i, j)$ represent the distance to $X$ and $Y$ axis of the $t$ th cutter.

(4) Torques. The load torque is generated by the tangential forces, which is equal to the resultant torque of each tangential force around $Z$ axial. Consider

$$
T_{L}=\sum_{i=1}^{n} F_{r i} \rho_{i}+\sum_{j=1}^{m} F_{r j} \rho_{j}+\sum_{k=1}^{p} F_{r k} \rho_{k} .
$$

The input torque $T_{p i}$ is equal to $1 / N$ times the load torque without considering power loss.

\subsection{Internal Excitations of TBM Cutterhead System}

3.2.1. Time-Varying Meshing Stiffness of Gear Pairs. For spur gears, the meshing stiffness shows obvious nature of the step period, which will change suddenly when the coincidence degree is not an integer, leading to the generation of the dynamic excitation force [20]. According to GB3480-1997, the peak and the average of meshing stiffness can be obtained. Then, the meshing stiffness variation can be modeled by a series of square wave functions. Finally, it is expanded in Fourier series without higher-order terms as follows:

$$
k(t)=k_{m}+\sum_{i=1}^{n}\left[k_{p i} \sin (i \omega t)+k_{c i} \cos (i \omega t)\right],
$$

where $\omega$ is meshing frequency, $n$ is the harmonic number of the meshing stiffness, $k_{m}$ is mean meshing stiffness, and $k_{p i}$ and $k_{c i}$ represent the amplitude of the $i$ th order sinusoidal and cosine magnitude, respectively.

3.2.2. Error Excitations of System. The error excitations can be modeled by harmonic functions [21]. The main errors considered in this study are as follows: manufacturing error $E_{r}$, installation error $A_{r}$, tooth thickness deviation $\varepsilon_{r}$, and profile error $\delta_{r}$ in the inner ring gear, with the corresponding parameters in the pinions $A_{p j}, \varepsilon_{p j}$, and $\delta_{p j}$, as well as the eccentric error $E_{p j}$. Accordingly, the equivalent accumulated error caused by the aforementioned errors, along with the internal meshing line takes the form

$$
\begin{aligned}
\varepsilon_{p r j}(t)= & E_{r} \sin \left(\omega_{r} t+\alpha+\varphi_{j}-\beta_{r}\right)+A_{r} \sin \left(\alpha+\varphi_{j}-\gamma_{r}\right) \\
& +E_{p j} \sin \left(\omega_{p} t+\alpha-\beta_{p i}\right)+A_{p j} \sin \left(\alpha-\gamma_{p j}\right) \\
& +\varepsilon_{r}+\varepsilon_{p j}+\sigma_{r}+\sigma_{p j} \quad(j=1-8),
\end{aligned}
$$

where $\alpha$ is meshing angle, $\beta$ and $\gamma$ are the phase angles of errors, and $\omega_{p}$ and $\omega_{r}$ represent the angular velocity of pinion and ring gear, respectively.

3.2.3. Support Equivalent Stiffness of Pinions. Each pinion bears the radial load, so the support equivalent stiffness is calculated by the following empirical formula [22]:

$$
K_{r}=0.34 \times 10^{4} F_{r}^{0.1} Z^{0.9} l^{0.8}(\cos \beta)^{1.9},
$$


where $F_{r}$ is radial load, $Z$ is the number of rollers, $l$ is the effective contact length of rollers, and $\beta$ is the contact angle of rollers.

3.2.4. Torsional Stiffness of Shaft Connections. According to Mechanics of Materials, the torsional stiffness of shaft connections can be expressed as

$$
k_{\mathrm{Q}}=\frac{G I_{p}}{L},
$$

where $I_{p}$ is the polar moment of inertia, $G$ is shear modulus, and $L$ is the equivalent length of shaft connections.

3.2.5. Stiffness of the Main Bearing. Since the positive thrust rollers and negative thrust rollers belong to radial-thrust bearing, the axial stiffness is defined as [23]

$$
\begin{gathered}
F_{a}=K_{n} Z(\sin \Psi)^{n+1} \delta_{a}^{n}, \\
K_{a}=\frac{d F_{a}}{d \delta_{a}}=n K_{n} Z(\sin \Psi)^{n+1} \delta_{a}^{n-1}, \\
K_{n}=2.89 \times 10^{4} l_{e}^{0.82} D_{w}^{0.11},
\end{gathered}
$$

where $F_{a}$ is the axial load of the bearing, $n$ is equal to 1.11 about the roller bearing, $K_{n}$ is stiffness coefficient, $Z$ is the number of rollers, $\Psi$ is the contact angle of rollers, $\delta_{a}$ is the axial displacement of the bearing, $l_{e}$ is the effective contact length of rollers, and $D_{w}$ is the effective diameter of rollers.

3.2.6. Meshing Damping Coefficient. The meshing damping coefficient is calculated by the following empirical formula [20]:

$$
C_{p r}=2 \varsigma \sqrt{\frac{k(t) m_{1} m_{2}}{\left(m_{1}+m_{2}\right)}},
$$

where $\varsigma$ is meshing damping ratio, which is equal to $0.03-0.17$, with the value of 0.03 in this study.

\subsubsection{Torsional Damping Coefficient of Shaft Connections.} The torsional damping coefficient of shaft connections is expressed as [20]

$$
C_{\mathrm{Q}}=2 \xi_{\mathrm{Q}} \sqrt{\frac{k_{\mathrm{Q}} I_{m} I_{p}}{\left(I_{m}+I_{p}\right)}}
$$

where $\xi_{\mathrm{Q}}$ is torsional damping ratio, which is equal to $0.005-$ 0.075 , with the value of 0.005 in this study.

3.2.8. Other Stiffness and Damping Coefficient. The stiffness of other components, such as cutterhead and support shield body, is calculated by using the finite element method (FEM). And the damping coefficient is calculated by the following formula [24]:

$$
c=2 \xi \sqrt{m_{e} k_{e}}
$$

where $\xi$ is damping ratio, which is equal to $0.02-0.05$, when the steel is in elastic stage, with the value of 0.02 in this study, and $m_{e}$ and $k_{e}$ is equivalent mass and equivalent stiffness, respectively.

\section{Solution of the Dynamic Model}

There are not good theoretical methods for solving the dynamic equation (12), because of the characteristics of multifactor coupling, strong nonlinear, time-varying, and randomness of the parameters. Thus, an interpolating algorithm of scattered data is presented, using the fourth-order RungeKutta integration method, to solve the dynamic system with an approximate solution. A flowchart of the solution is shown in Figure 5.

\section{Engineering Project Example}

Taking the cutterhead system of the hard rock TBM of a water tunnel project as a background, an application instance is presented. The relative parameters are as follows: (1) cutterhead geometry: the cutterhead diameter $D=8.53 \mathrm{~m}$, the mass of cutterhead $M=200 \mathrm{t}$, the cutter penetration $P=$ $10 \mathrm{~mm}$, the center cutter number $n=4$, the normal cutter number $m=34$, the gauge cutter number $p=12$, and the disc cutters' plane layout is shown in Figure 6; (2) parameters of the driving system: the driving power $W=3440 \mathrm{~kW}$, the angular velocity of cutterhead $\omega=5.6 \mathrm{r} / \mathrm{min}=0.5861 \mathrm{rad} / \mathrm{s}$, the number of pinions $N=8$, the tooth number of inner ring gear $Z_{r}=174$, the tooth number of each pinion $Z_{p}=14$, the module $m=22$, and the error excitations can be obtained according to Mechanical Design Handbook [24]; (3) rock physical properties: the typical rock is mainly granite gneiss geology, and for detailed mechanical parameters see [12].

5.1. Calculation of External Excitations. Based on the field data $[5,6]$ and simulation's loads of rock breaking under the action of multicutters, combined with the above assumptions, the load-time histories of three types of cutters (center cutters, normal cutters, and gauge cutters) can be obtained, partially shown in Figure 7.

As can be seen in Figure 7, the loads of cutters composed of a series of impact loads show obvious nature of the step period and increase with the cutting depth of cutters in a cycle of rock breaking, which is identical with the engineering experience.

According to formulas (13)-(16), we can obtain the external excitations of cutterhead system, using Fast Fourier Transform (FFT) algorithm to generate the spectral responses. Due to space limitation, this paper only presents the frequency responses of radial force, axial force, and torque in center block, as shown in Figure 8.

Figure 8 shows that there are lots of frequency components in the spectral responses, mainly in $0-10 \mathrm{~Hz}$, which is in agreement with the conclusion in $[5,6]$. Moreover, the remaining energy is concentrated in these typical frequency ranges, such as $100-120 \mathrm{~Hz}, 230-260 \mathrm{~Hz}, 340-390 \mathrm{~Hz}$, and $680-700 \mathrm{~Hz}$. 


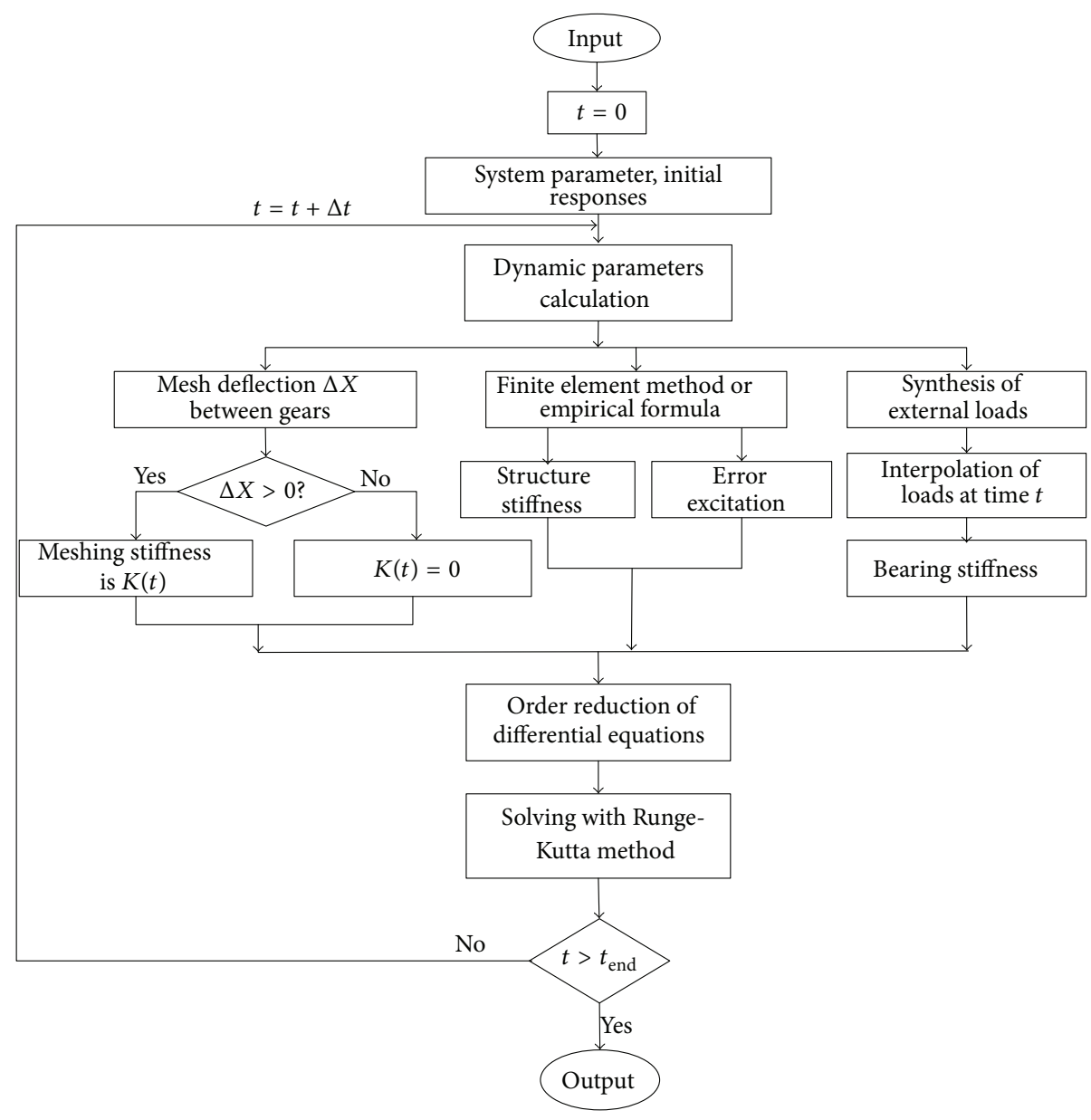

FIGURE 5: Solution flowchart of the dynamic model.

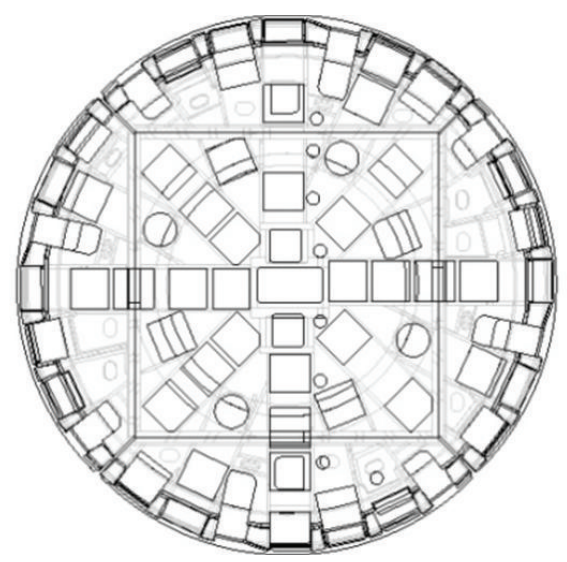

FIgURE 6: Layout of cutters.

5.2. Analysis of Modal Properties. The free vibration of the linear, time-invariant representation is considered, ignoring the damping coefficient and external excitations in formula (12). Since there is 59 degrees of freedom in the dynamic system, we can obtain 59 natural frequencies and mode
TABLE 1: Natural frequencies and vibration of the cutterhead system.

\begin{tabular}{lc}
\hline Vibration modes & Natural frequencies/Hz \\
\hline $\begin{array}{l}\text { Rigid mode } \\
\text { Rotational vibration of pinions } \\
\text { and motors }\end{array}$ & $f_{1}=0$ \\
$\begin{array}{l}\text { Translational and overturning } \\
\text { coupled vibration of cutterhead }\end{array}$ & $f_{2-9}=57$ \\
and inner ring gear & $f_{10}=61, f_{11}=70$, \\
& $f_{12}=114, f_{13,14}=120$, \\
& $f_{15}=124$ \\
\hline
\end{tabular}

shapes, and the lowest fifteen natural frequencies are listed in Table 1.

The vibration modes with normalization are illustrated in Figure 9, where the freedom number 1-59 is the corresponding degree of freedom, respectively.

The main conclusions obtained through Table 1 and Figure 9 are as follows.

(1) The first natural vibration mode is rigid mode, with the rigid motion of inelastic deformation, which keeps the constant transmission ratio to each rotational part. 


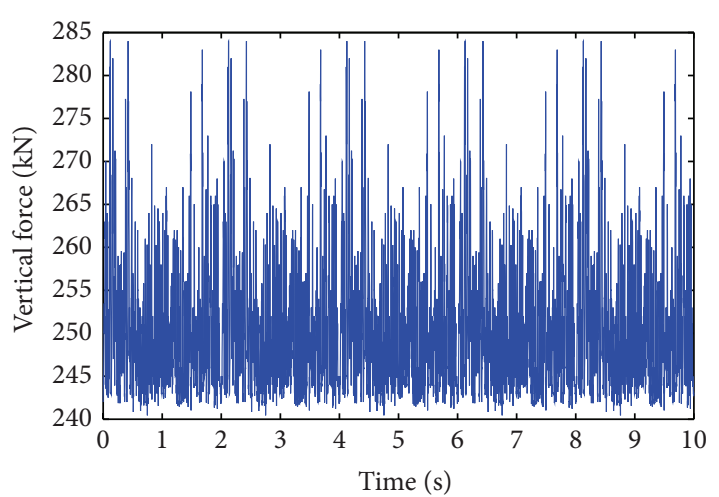

(a) Normal forces of center cutters

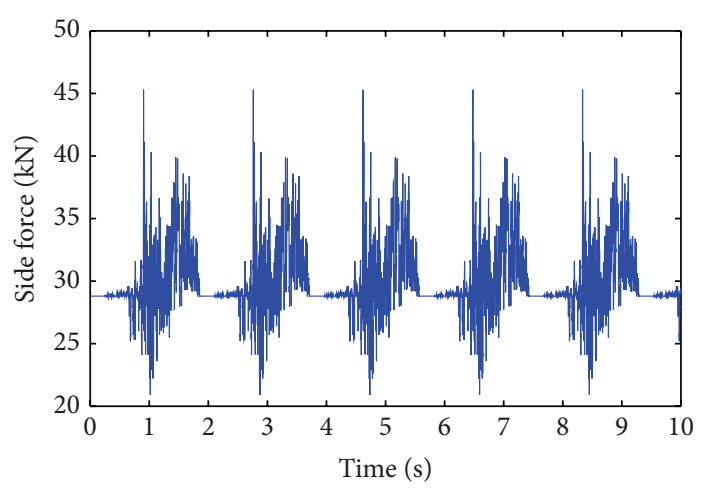

(c) Side forces of normal cutters

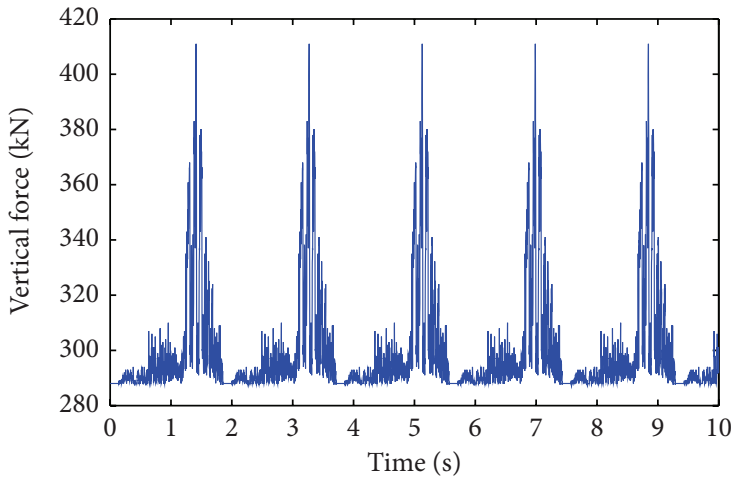

(b) Normal forces of normal cutters

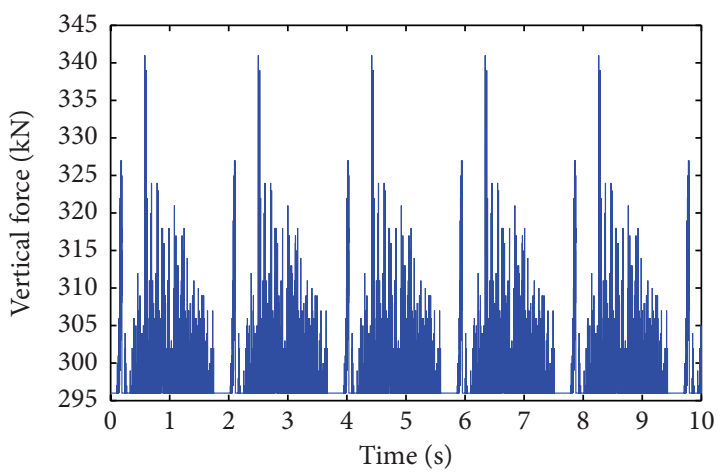

(d) Normal forces of gauge cutters

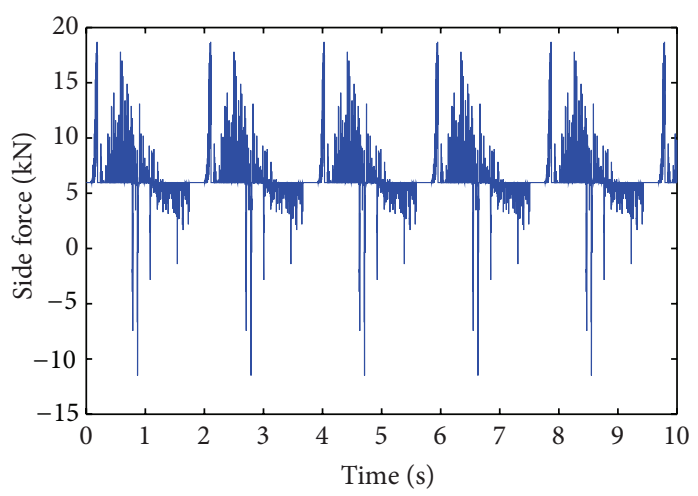

(e) Side forces of gauge cutters

FIGURE 7: Loads time history of cutters.

(2) The amplitudes of free vibration are mainly in the middle order modes, and the low and high order modes are relatively smaller.

(3) The lowest fifteen natural vibration modes are mainly rotational vibration of pinions and motors and translational and overturning coupled vibration around arbitrary axis of cutterhead and inner ring gear, which is consistent with the engineering example in [25]. In addition, the low natural frequencies are $57 \mathrm{~Hz}$ and $61 \mathrm{~Hz}$, which are greater than the rotation frequency of pinions $(1.16 \mathrm{~Hz})$ and meshing frequency $(16.24 \mathrm{~Hz})$ of internal excitations. Nevertheless, the resonance of the cutterhead system may be inevitable with the current parameters, due to the wide frequency of external excitations.

5.3. Dynamic Responses and Analysis. With the first $2 \mathrm{~s}$ of external excitations, we can obtain the dynamic responses of cutterhead, as shown in Figures 10 and 11.

From the dynamic results, Figure 10 can draw the following conclusions.

(1) The vibration amplitudes of cutterhead pieces in each direction are less than $1 \mathrm{~mm}$, which shows that the stiffness of cutterhead system is relatively high to resist the impact of external excitations. 


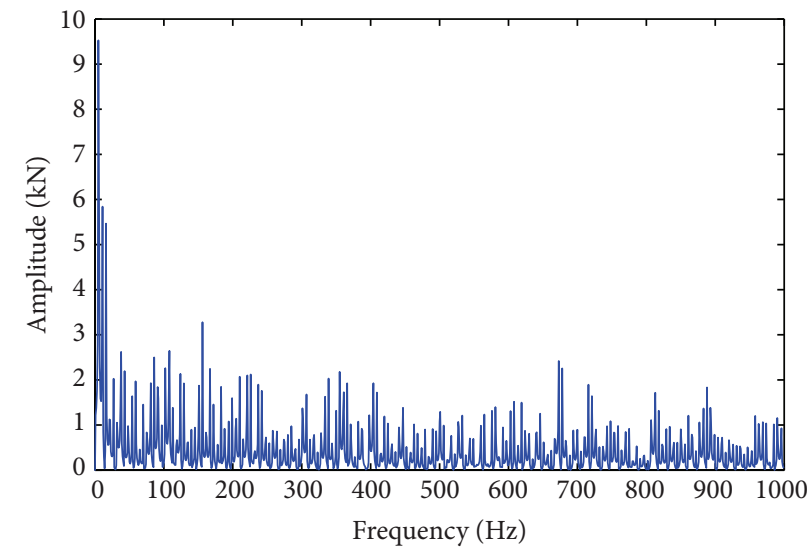

(a) Frequency spectrum results of radial force

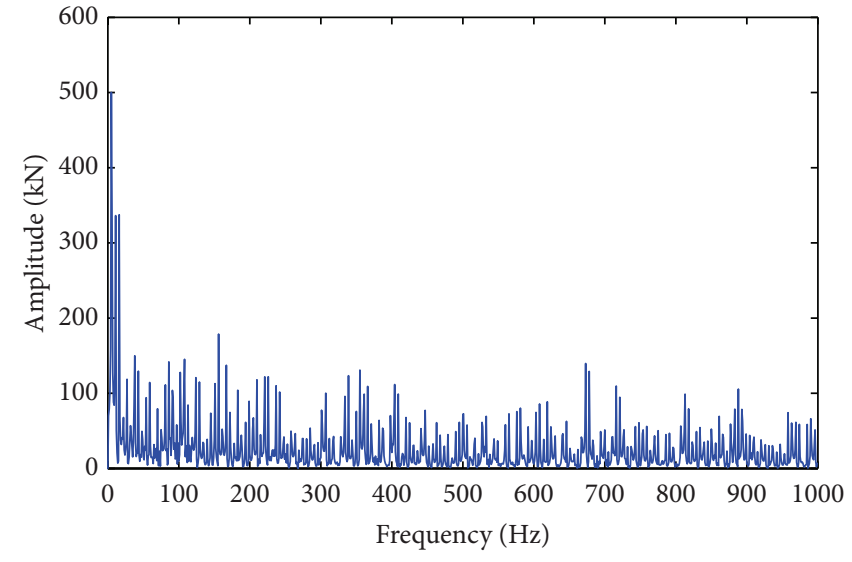

(b) Frequency spectrum results of axial force

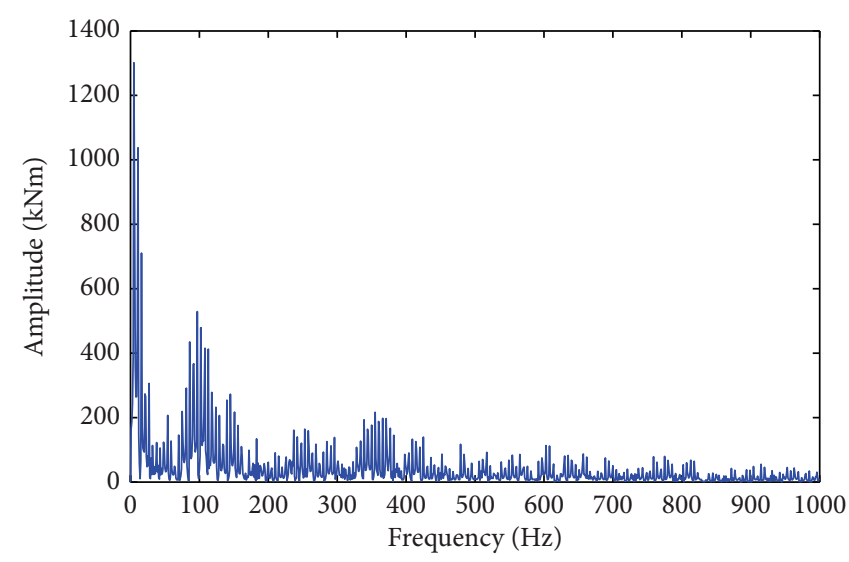

(c) Frequency spectrum results of torque

FIGURE 8: Frequency spectrum results of external excitations.

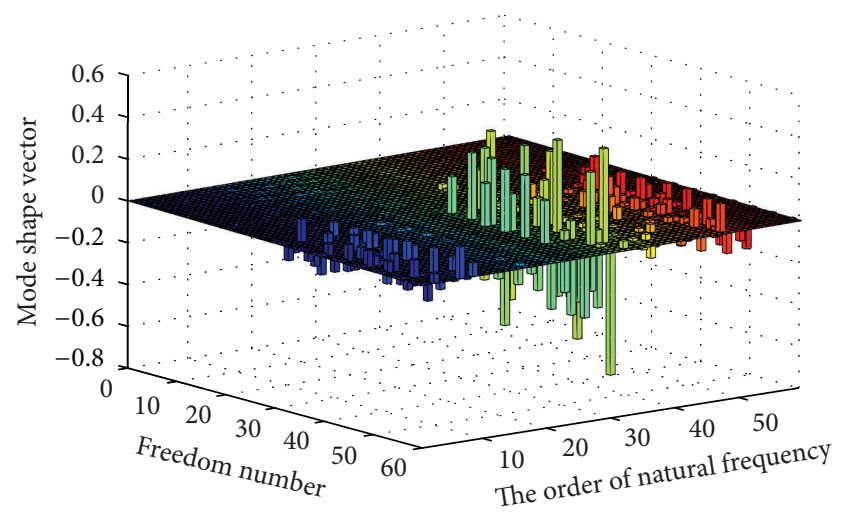

FIGURE 9: Vibration modes of the cutterhead system.

(2) The vibration in each direction is similar to the variation of external excitations, which is influenced greatly.

(3) The magnitude of amplitude in each cutterhead piece is identical, where the axial vibration is maximal, with the amplitude being up to about $0.55 \mathrm{~mm}$. And the maximum amplitude of radial direction is close to $0.25 \mathrm{~mm}$. It is shown that although the radial force is much less than axial force, the radial stiffness is also relatively lower, which can explain the cause of identical magnitude in each direction. However, the radial vibrations have stronger influence on the cutterhead driving system, which may cause some engineering problems, such as seal failure and abnormal wears of the bearing raceway.

Similar conclusions may be obtained from Figure 11 as follows.

(1) The vibration regularity of center block is consistent with cutterhead pieces, and the amplitude in each direction is slightly smaller, with the maximum amplitude of $0.48 \mathrm{~mm}$ in axial direction and $0.2 \mathrm{~mm}$ in radial directions. These responses of translational vibration provide input conditions for calculating the joint surface loads of cutterhead.

(2) The maximum angular amplitude around $X$ and $Y$ axes is about $0.016 \mathrm{mrad}$, while the torsional amplitude around $Z$ axis is about $0.065 \mathrm{mrad}$, which has a great effect on cutters' wear and weld of cutterhead support ribs, and it may cause abnormal wears of the disc cutters, weld cracking, and other engineering problems. 


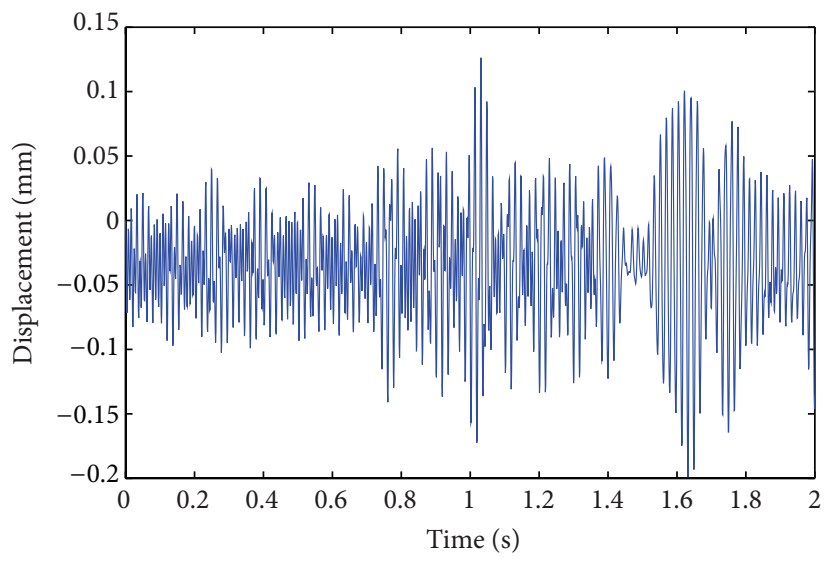

(a) Displacement in $\zeta$ direction

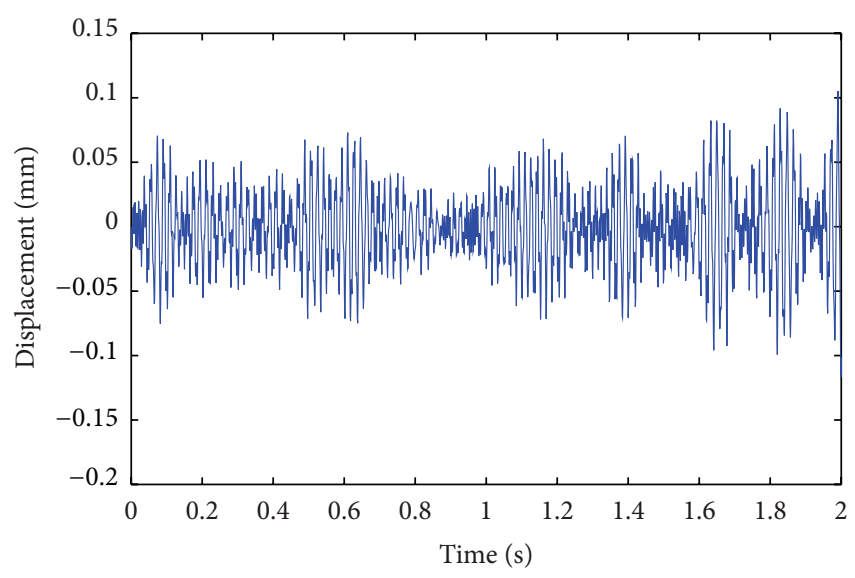

(b) Displacement in $\eta$ direction

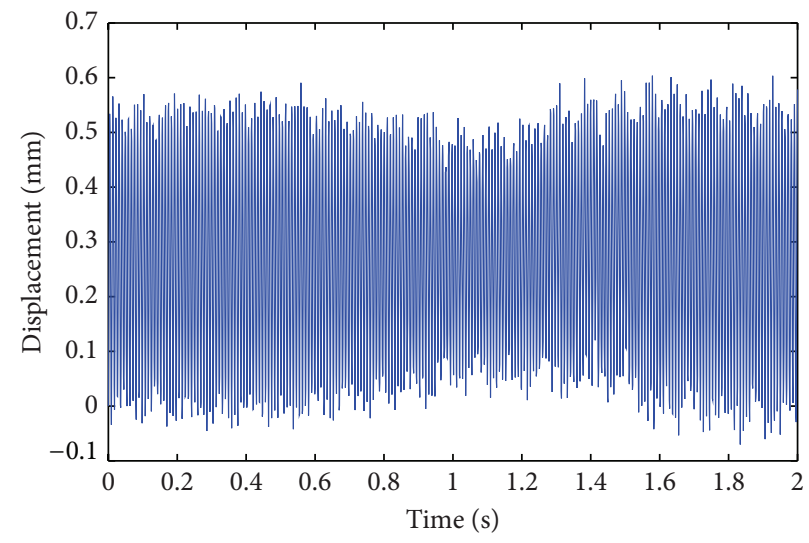

(c) Displacement in $Z$ direction

FIGURE 10: Dynamic responses of cutterhead pieces.

The comparison of Figure 10 with Figure 11 shows that the translational vibration responses between cutterhead pieces and center block are analogous, and the amplitudes are almost the same. The reason is that each cutterhead piece is attached to the center block, and the connection stiffness is relatively large compared to the external excitations. That is, each cutterhead piece vibrates with the center block, which illustrates that the amplitude of each cutterhead piece is slightly larger than that of the center block. The translational responses of Figures 10 and 11 certificate this regularity.

Thus, as the results mentioned above, it is illustrated that the proposed model and method are effective and correct.

The dynamic responses of cutterhead system are not only related to the time domain but also affected by the frequency; thereby the Fast Fourier Transform (FFT) algorithm is used to generate the frequency responses, as shown in Figures 12 and 13.

As may be seen from the spectral analysis in Figures 12 and 13 , the following can be found.

(1) Under the influence of time-varying internal and external excitations, the main frequencies of dynamic responses are as follows: $100-120 \mathrm{~Hz}, 224 \mathrm{~Hz}, 236 \mathrm{~Hz}$,
$390 \mathrm{~Hz}$, and $693 \mathrm{~Hz}$, which are consistent with external excitations. It is indicated that the vibration type of cutterhead belongs to forced vibration; in other words, the dynamic responses are influenced by the external excitations more greatly.

(2) The frequencies of radial, torsional, and overturning vibrations are concentrated in $112 \mathrm{~Hz}$ and $120 \mathrm{~Hz}$, which are in good agreement with the natural frequencies of the translational and overturning coupled vibration mode (listed in Table 1). It is suggested that the two frequencies should be mainly considered when cutterhead structure is designed and the boring parameters are matched, avoiding the resonance phenomenon due to the unreasonable selection of system parameters.

The comparison of frequency responses with the natural frequencies and external excitations shows that the frequencies are basically identical, which can further demonstrate the effectiveness of the proposed model and method.

Substituting the dynamic responses of cutterhead into (11), one can obtain tangential and radial relative deformations between each cutterhead piece and central block. 


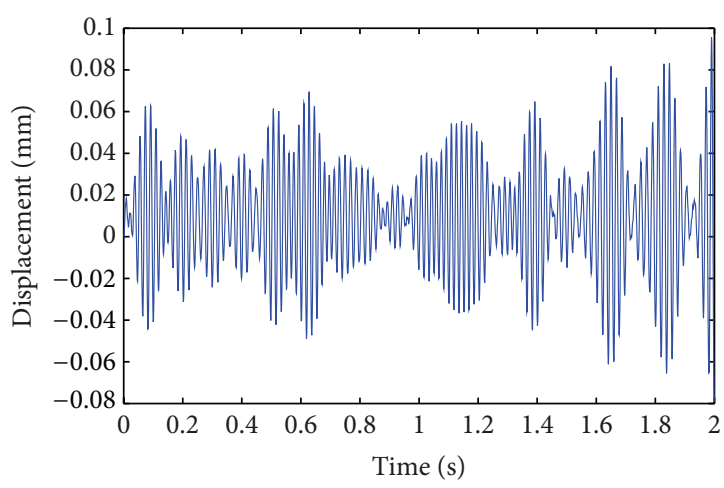

(a) Displacement in $X$ direction

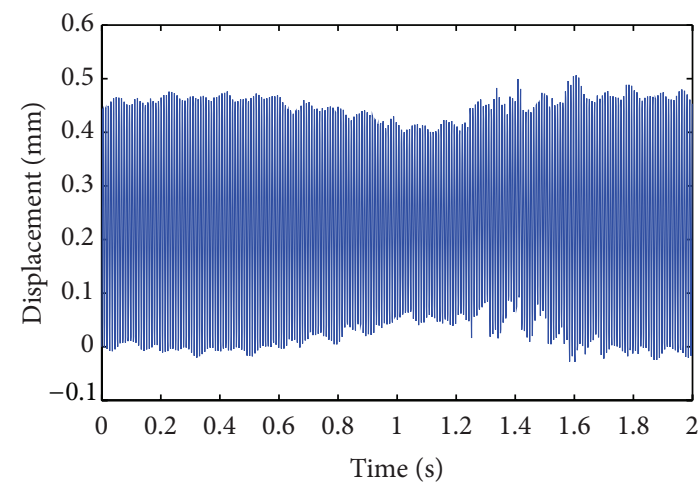

(c) Displacement in $Z$ direction

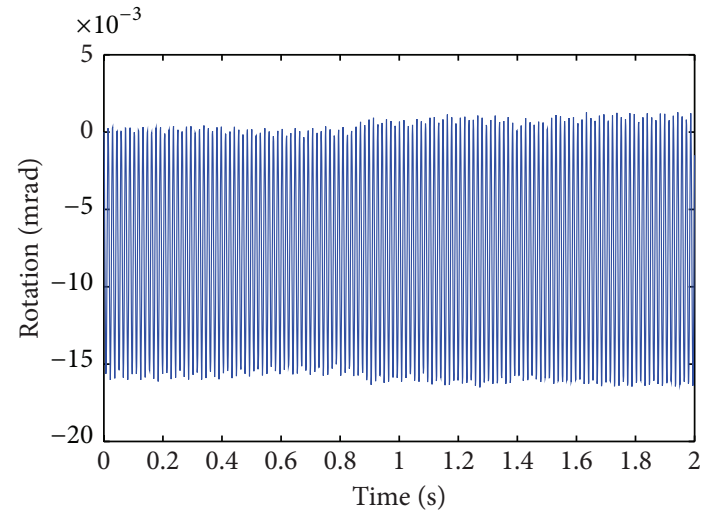

(e) Rotation in Ytorsion-swing direction

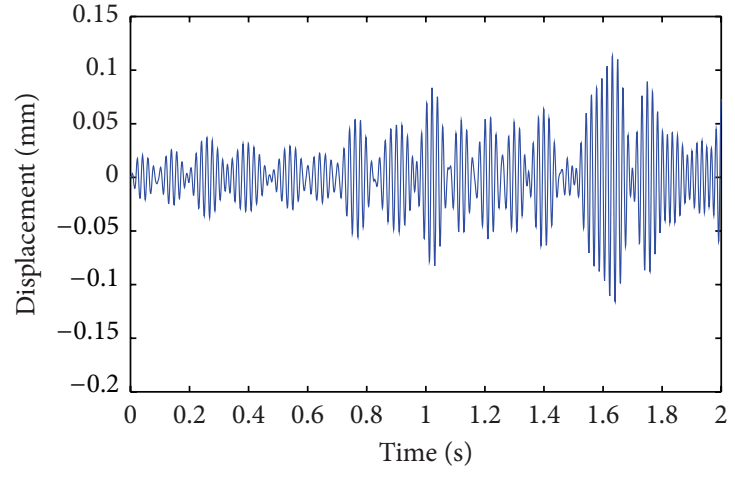

(b) Displacement in $Y$ direction

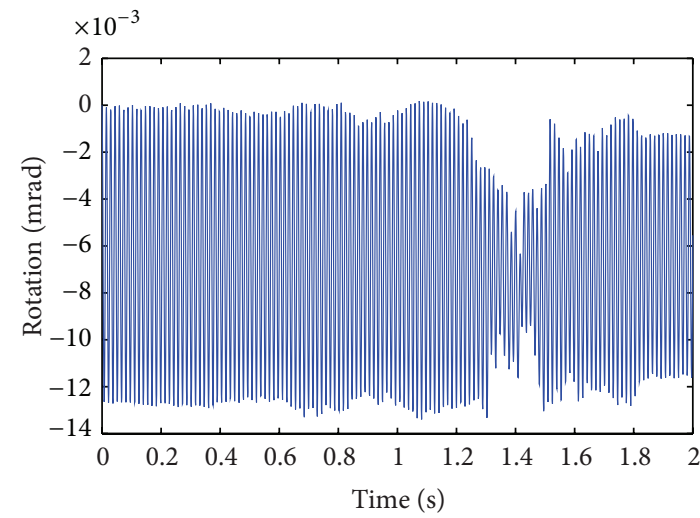

(d) Rotation in $X$ torsion-swing direction

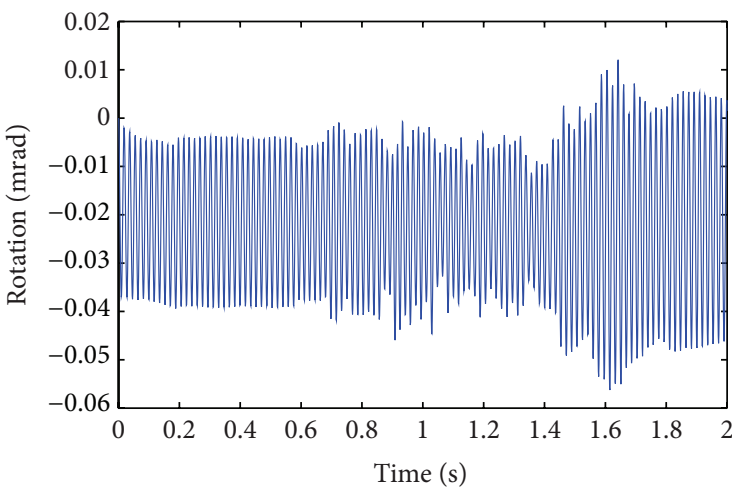

(f) Rotation in $Z$ torsion direction

FIGURE 11: Dynamic responses of the cutterhead center block.

Multiplying the corresponding equivalent support stiffness, the loads of cutterhead joint surface are gained, and, using the rain flow method, one can obtain the load range distributions, and the results are shown in Figure 14.

From the above-mentioned results, the distribution types and characteristic values can be estimated and tested by $K-S$ test. It is observed that the cutterhead joint surface loads approximately obey normal distribution, and the distribution parameters are listed in Table 2.

From the data in Figure 14 and Table 2, the following conclusions can be drawn.
(1) The cutterhead joint surface loads change rapidly with a considerable discrete degree, under the influence of complex factors.

(2) The mean of joint surface loads are highly consistent with the external excitations (minus represents the direction), while the standard deviation in each direction increases by $12-15$ times. It is indicated that the obtained simulation results are correct from the results of mean joint surface loads, and the inertial effect should be considered for the structure design of cutterhead, combined with dynamic analysis. 


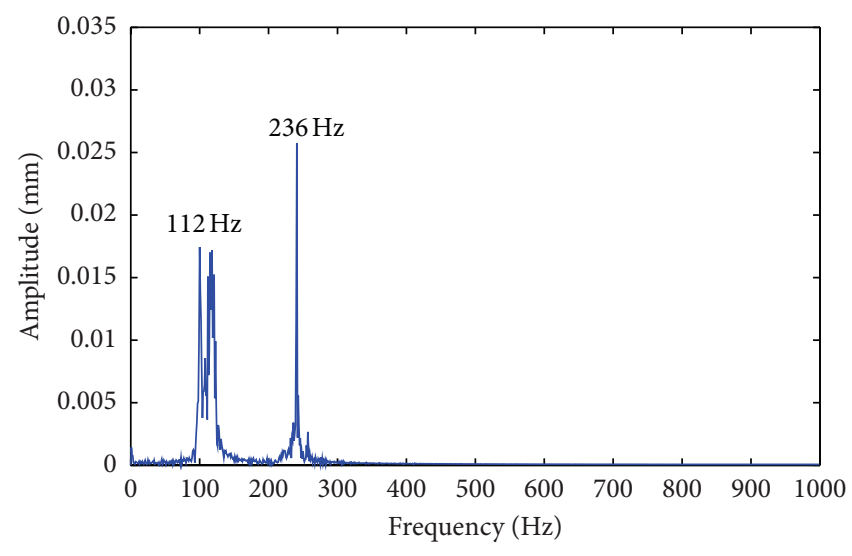

(a) Frequency responses in $\zeta$ direction

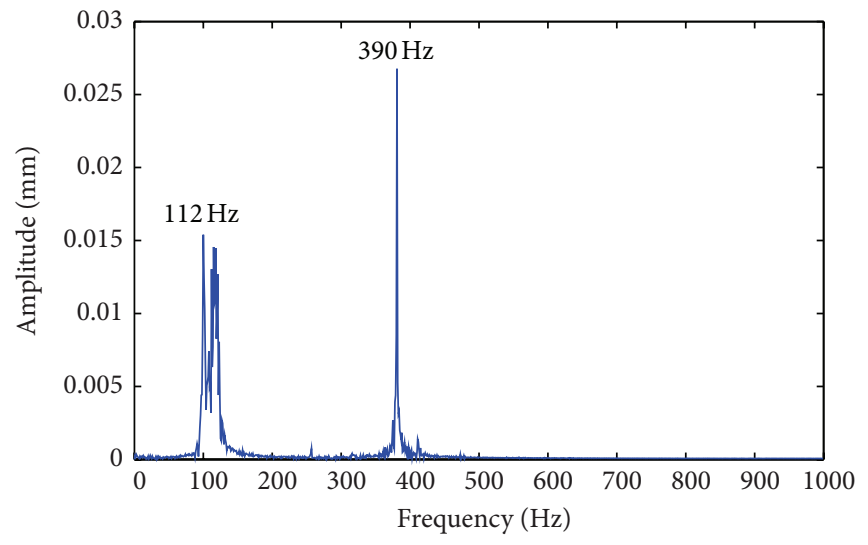

(b) Frequency responses in $\eta$ direction

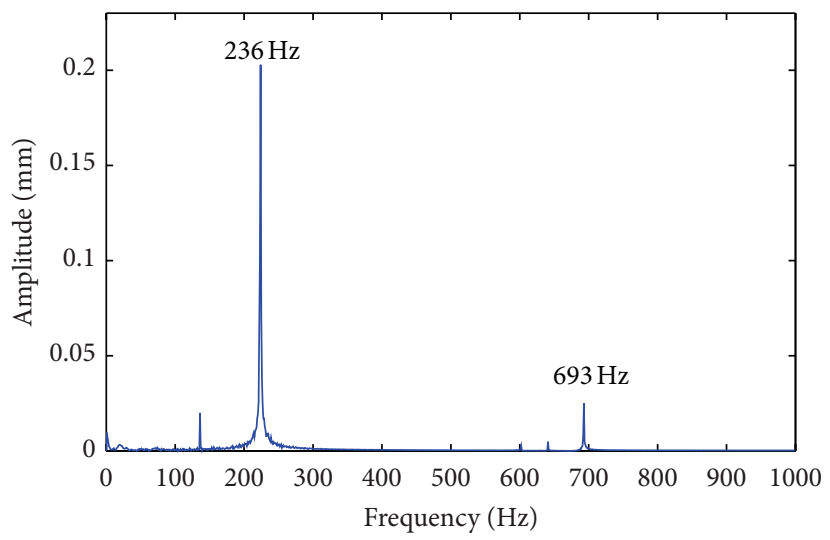

(c) Frequency responses in $Z$ direction

FIGURE 12: Frequency responses of the cutterhead pieces.

TABLE 2: Distribution statistics of the cutterhead joint surface loads.

\begin{tabular}{lcccc}
\hline & \multicolumn{2}{c}{ Joint surface loads } & \multicolumn{2}{c}{ External excitations } \\
& Mean/kN & Standard deviation/kN & Mean/kN & 139.66 \\
Tangential & -139.69 & 93.25 & 106.32 & 7.40 \\
Normal & -106.27 & 130.03 & 1410.55 & 11.04 \\
Axial & 1410.55 & 915.48 & 60.00 \\
\hline
\end{tabular}

These simulation results can provide boundary conditions for dynamic performance optimization and crack propagation of the cutterhead structure.

\section{Conclusions}

In this paper, a multidegree-of-freedom coupling dynamic model is presented for the TBM cutterhead system. Based on the parameters of an actual project and the cutters' forces, the structured modal properties and dynamic responses are analyzed. The main results are summarized as follows.

(1) The lowest fifteen natural vibration modes of the cutterhead system are classified as rigid mode, rotational vibration modes of pinions and motors, and translational and overturning coupled vibration modes of cutterhead and inner ring gear, and the corresponding natural frequency is $57 \mathrm{~Hz}$ and $61 \mathrm{~Hz}$, which is greater than rotation frequency of pinions and meshing frequency of internal excitations. However, the resonance of the cutterhead system may be inevitable due to the overlap frequencies between natural frequencies and external excitations.

(2) The vibration responses of cutterhead are similar to the variation of external excitations, with the identical magnitude of amplitude in each translational direction, where the axial amplitude is about $0.55 \mathrm{~mm}$, 


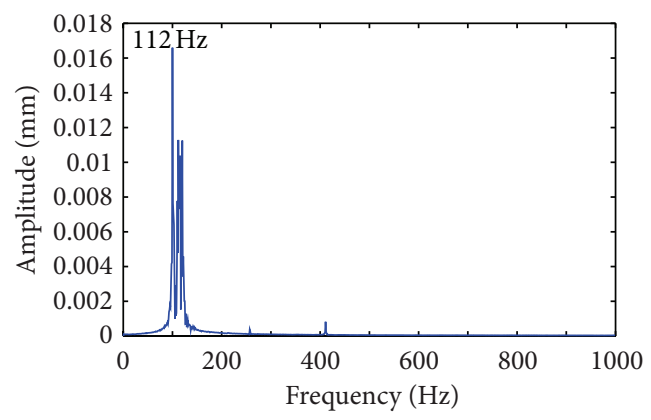

(a) Frequency responses in $X$ direction

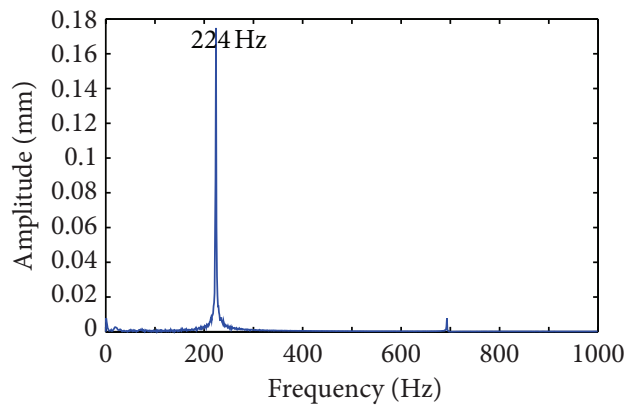

(c) Frequency responses in $Z$ direction

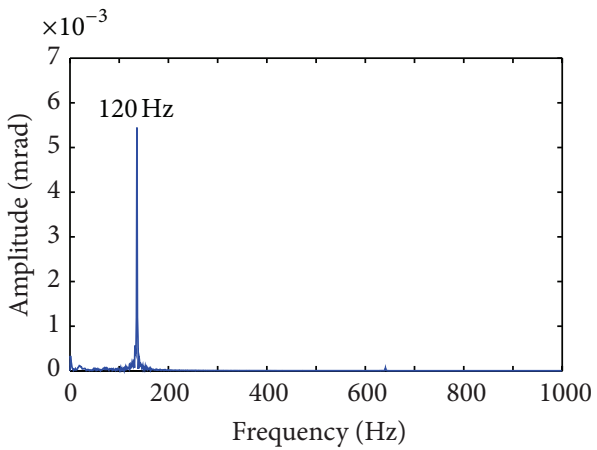

(e) Frequency responses in $Y$ torsion-swing direction

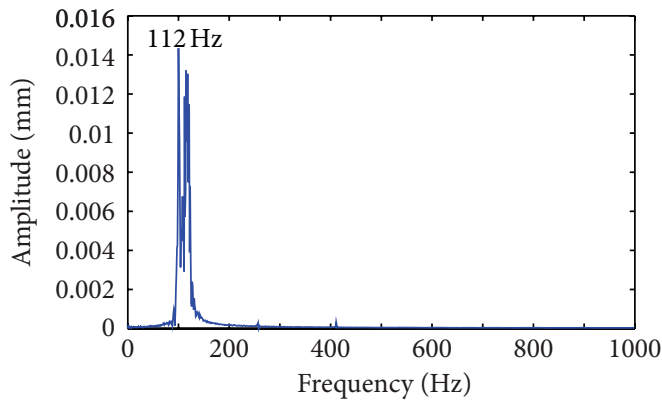

(b) Frequency responses in $Y$ direction

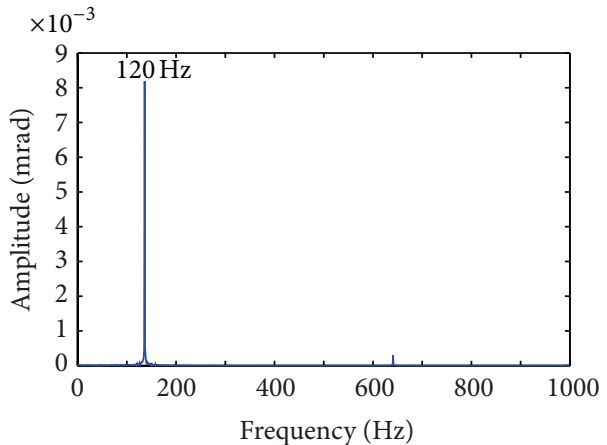

(d) Frequency responses in $X$ torsion-swing direction

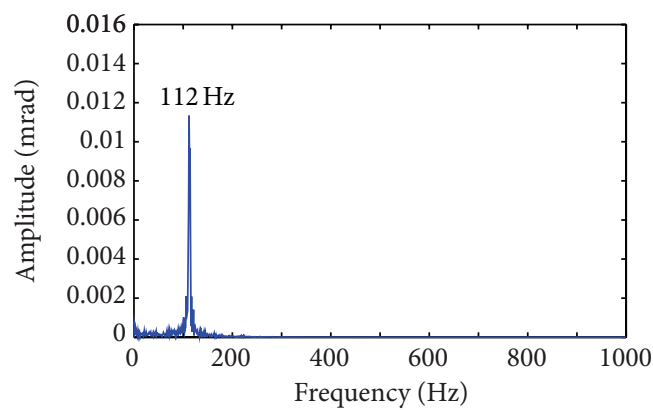

(f) Frequency responses in $Z$ torsion direction

FIGURE 13: Frequency responses of the cutterhead center block.

the radial amplitude is close to $0.25 \mathrm{~mm}$, the angular amplitude around $X$ and $Y$ axes is about $0.016 \mathrm{mrad}$, and the torsional amplitude is almost $0.065 \mathrm{mrad}$. The results may provide reference for the design of cutterhead driving system and weld strength check of support ribs.

(3) The frequencies of dynamic responses are predominantly concentrated in $100-120 \mathrm{~Hz}, 224 \mathrm{~Hz}, 236 \mathrm{~Hz}$, $390 \mathrm{~Hz}$, and $693 \mathrm{~Hz}$. And it is suggested that the two frequencies of $112 \mathrm{~Hz}$ and $120 \mathrm{~Hz}$ should be avoided, while carrying out the structural design of cutterhead and matching the boring parameters.

(4) Considering the influence of internal and external excitations, it is shown that the cutterhead joint surface loads change rapidly with large amplitudes, as well as complex nonlinear characteristics. As the rain flow results have shown, the standard deviation in each direction increases by $12-15$ times. It is indicated that the amplification effect of dynamic loads should be mainly considered in cutterhead structural design, so as to lay a foundation for dynamic optimization and fatigue life assessment of the cutterhead structure.

There are some further topics that should be studied, although we have obtained many effective results about TBM cutterhead system. In the next stage, we will study the parameter influence laws about dynamic characteristics, estimate the fatigue life of the cutterhead based on the joint surface loads, and carry out the field test and vibration experiment in the near further. 


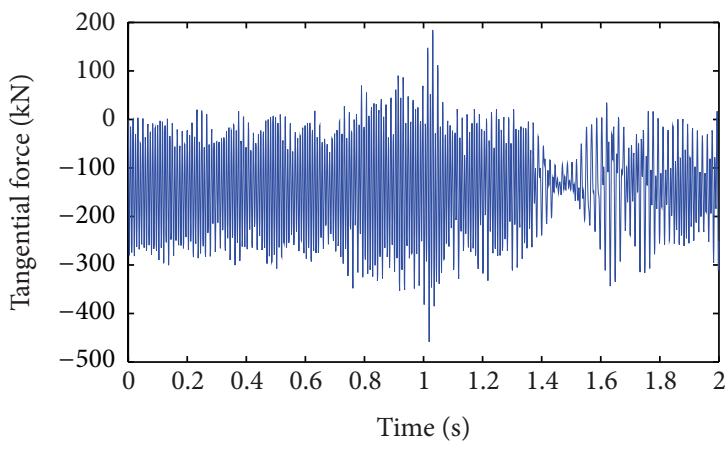

(a) Time history of the tangential force

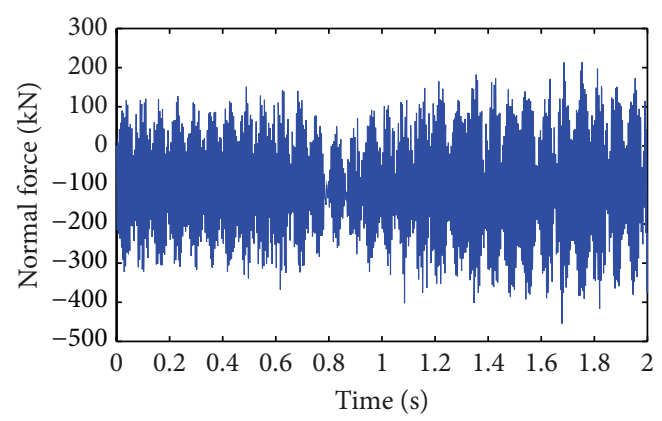

(c) Time history of the normal force

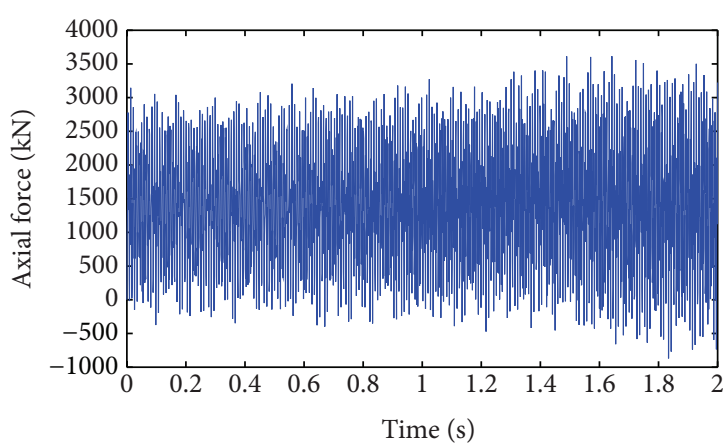

(e) Time history of the axial force

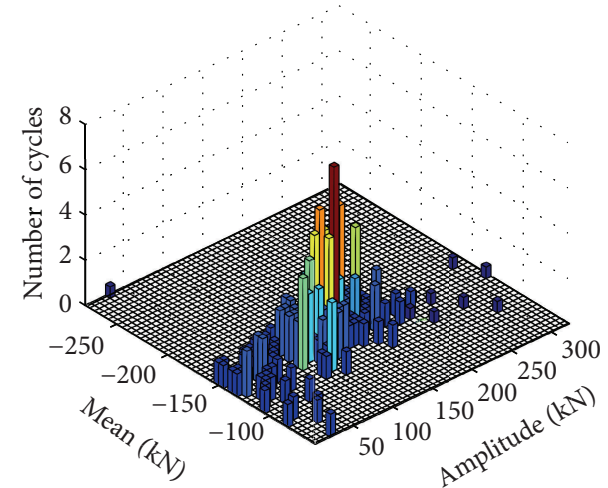

(b) Rain flow counting statistics of the tangential force

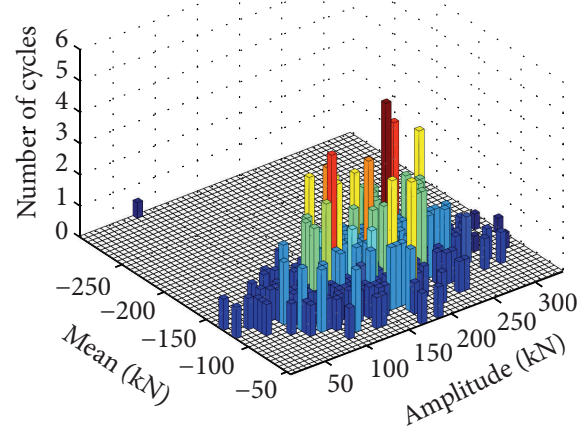

(d) Rain flow counting statistics of the normal force

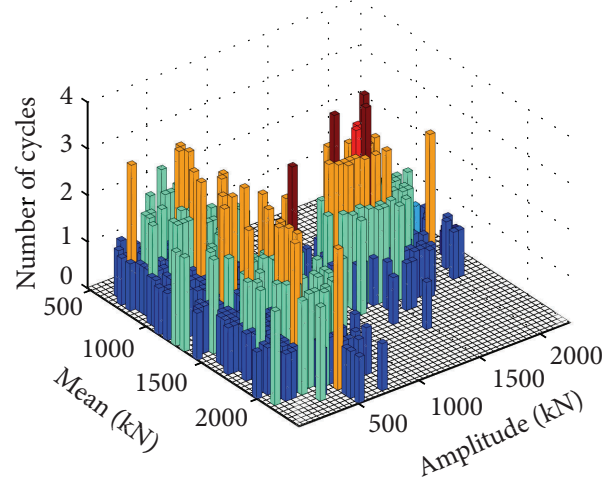

(f) Rain flow counting statistics of the axial force

FIGURE 14: Time-varying histories and statistics results of the cutterhead joint surface loads.

\section{Conflict of Interests}

The authors declare that there is no conflict of interests regarding the publication of this paper.

\section{Acknowledgments}

This work is supported by the National Natural Science Foundation of China (Grant no. 51005033 and no. 51375001), Development Program of China (973 Program) (Grant no. 2013CB035400), National Key Technologies R\&D Program of Liaoning Province (Grant no. 2011220031), and the Fundamental Research Specific Funded Program of Central University (Grant no. DUT13LK14). The authors gratefully acknowledge the reviewers and editors for their helpful comments and suggestions, which have improved the research.

\section{References}

[1] Promotion Center for Science \& Technology Achievements of Ministry of Water Resources, Full Face Rock Tunnel Boring Machine (TBM), Petroleum Industry Press, Beijing, China, 2005 (Chinese). 
[2] H. L. Li, "Troubleshooting for cutter disk cracking of model TB880 rock tunneler," Construction Machinery and Equipment, vol. 41, no. 3, pp. 62-67, 2010 (Chinese).

[3] Y. J. Wang, "Analysis of the causes of failures and maintenance techniques for the main bearing of the TBM," Traffic Engineering and Technology for National Defence, no. 2, pp. 46-49, 2011 (Chinese).

[4] M. X. Qi, Y. J. Wang, and H. L. Li, "Research and application of overall refit of open type TBM," Modern Tunnelling TechNology, vol. 46, no. 4, pp. 64-70, 2009 (Chinese).

[5] A. E. Samuel and L. P. Seow, "Disc force measurements on a full-face tunnelling machine," International Journal of Rock Mechanics and Mining Sciences \& Geomechanics Abstracts, vol. 21, no. 2, pp. 83-96, 1984.

[6] Z. X. Zhang, S. Q. Kou, and P.-A. Lindqvist, "In-situ measurements of cutter forces on boring machine at Äspö Hard Rock Laboratory," Rock Mechanics and Rock Engineering, vol. 36, no. 1, pp. 63-83, 2003.

[7] J. Rostami, "Hard rock TBM cutterhead modeling for design and performance prediction," Geomechanik Und Tunnelbau, vol. 1, pp. 18-28, 2008.

[8] L. H. Wang, Y. L. Kang, Z. X. Cai et al., "The energy method to predict disc cutter wear extent for hard rock TBMs," Tunnelling and Underground Space Technology, vol. 28, no. 1, pp. 183-191, 2012.

[9] Q. Zhang, C. Qu, Y. Kang et al., "Identification and optimization of energy consumption by shield tunnel machines using a combined mechanical and regression analysis," Tunnelling and Underground Space Technology, vol. 28, no. 1, pp. 350-354, 2012.

[10] Y. M. Xia, T. Ooyang, X. M. Zhang et al., "Mechanical model of breaking rock and force characteristic of disc cutter," Journal of Central South University, vol. 19, pp. 1846-1852, 2012.

[11] Q. Tang, M. J. Xu, Y. M. Xia et al., "Numerical study on mode of breaking rock by TBM cutter in two cutting orders," Journal of Central South University, vol. 43, no. 3, pp. 940-946, 2012 (Chinese).

[12] J. Huo, W. Sun, L. Guo, Z. Li, and X. Zhang, "Numerical simulation of the rock fracture process induced by multi-disccutters and cutter spacing design," Journal of Harbin Engineering University, vol. 33, no. 1, pp. 96-99, 2012 (Chinese).

[13] J. Z. Huo, W. Sun, J. Chen, and X. Zhang, "Disc cutters plane layout design of the full-face rock tunnel boring machine (TBM) based on different layout patterns," Computers \& Industrial Engineering, vol. 61, no. 4, pp. 1209-1225, 2011.

[14] W. Sun, J. Huo, J. Chen et al., "Disc cutters' layout design of the full-face rock tunnel boring machine (TBM) using a cooperative coevolutionary algorithm," Journal of Mechanical Science and Technology, vol. 25, no. 2, pp. 415-427, 2011.

[15] Z. Li, J. Z. Huo, W. Sun et al., "Cutterhead structure optimal design of the full-face rock tunnel boring machine," Machine Design \& Research, vol. 27, no. 1, article 90, pp. 83-86, 2011 (Chinese).

[16] K. Z. Zhang, Study on dynamic characteristics of redundantly driven revolving system of shield TBM [Ph.D. thesis], Shanghai Jiao Tong University, Shanghai, China, 2011 (Chinese).

[17] T. Sakanushi, J. Hu, K. Yamada et al., "The parameterization of all stabilizing two-degrees-of-freedom simple repetitive controllers and its application," International Journal of Innovative Computing Information and Control, vol. 9, no. 3, pp. 1271-1292, 2013.
[18] K. Yamada, N. Nakazawa, I. Murakami et al., "A design method for two-degree-of-freedom multi-period repetitive control systems," Key Engineering Materials, vol. 459, pp. 194-210, 2011.

[19] S. C. Martin and L. L. Whitcomb, "Preliminary experiments in comparative experimental identification of six degree-offreedom coupled dynamic plant models for underwater robot vehicles," in Proceedings of the IEEE International Conference on Robotics and Automation (ICRA '13), pp. 2962-2969, Karlsruhe, Germany, 2013.

[20] R. F. Li and J. J. Wang, Gear Transmission System Dynamics, Science Press, Beijing, China, 1997 (Chinese).

[21] J.-X. Zhou, G. Liu, and S.-J. Ma, "Vibration and noise analysis of gear transmission system," Journal of Vibration and Shock, vol. 30, no. 6, pp. 234-238, 2011 (Chinese).

[22] S. E. Deng and Q. Y. Jia, Design Principles of Rolling Bearings, Standards Press of China, Beijing, China, 2008 (Chinese).

[23] J. W. Luo and T. Y. Luo, The Calculation and Application of Rolling Bearings, Machinery Industry Press, Beijing, 2009 (Chinese).

[24] Mechanical Design Handbook Editorial Board, Mechanical Design Handbook Offprint Mechanical Vibration and Noise, Machinery Industry Press, Beijing, China, 2007 (Chinese).

[25] H. X. Zhang and N. C. Zhang, "Brief discussion on cutter head vibration of type 803E TBM," Tunnel Construction, vol. 27, no. 6, article 111, pp. 76-78, 2007 (Chinese). 


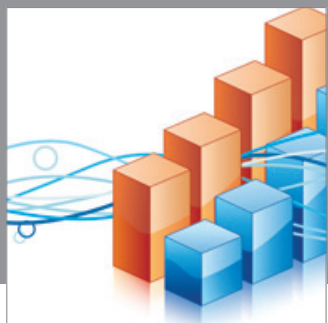

Advances in

Operations Research

mansans

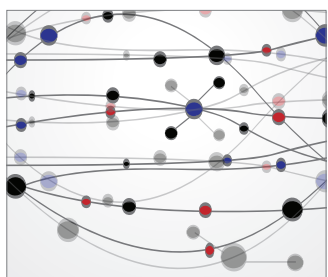

The Scientific World Journal
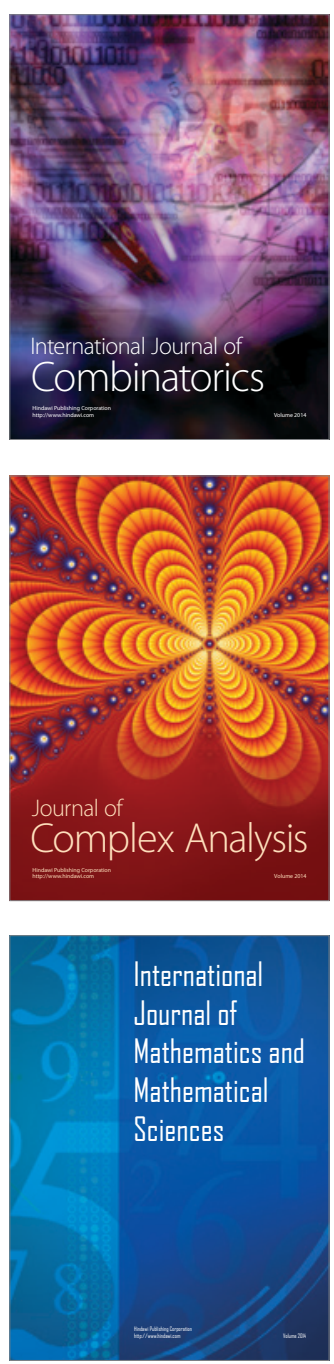
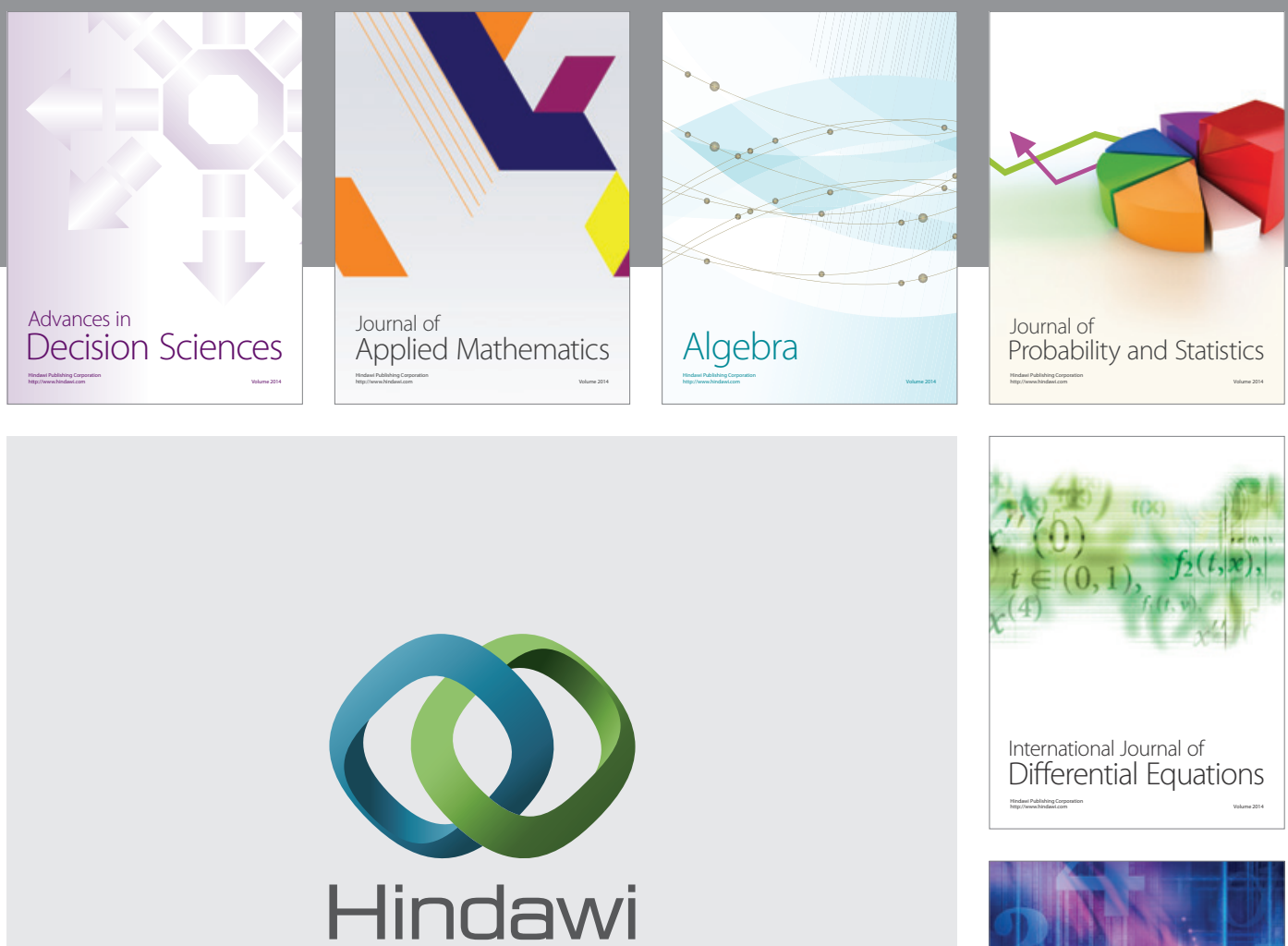

Submit your manuscripts at http://www.hindawi.com
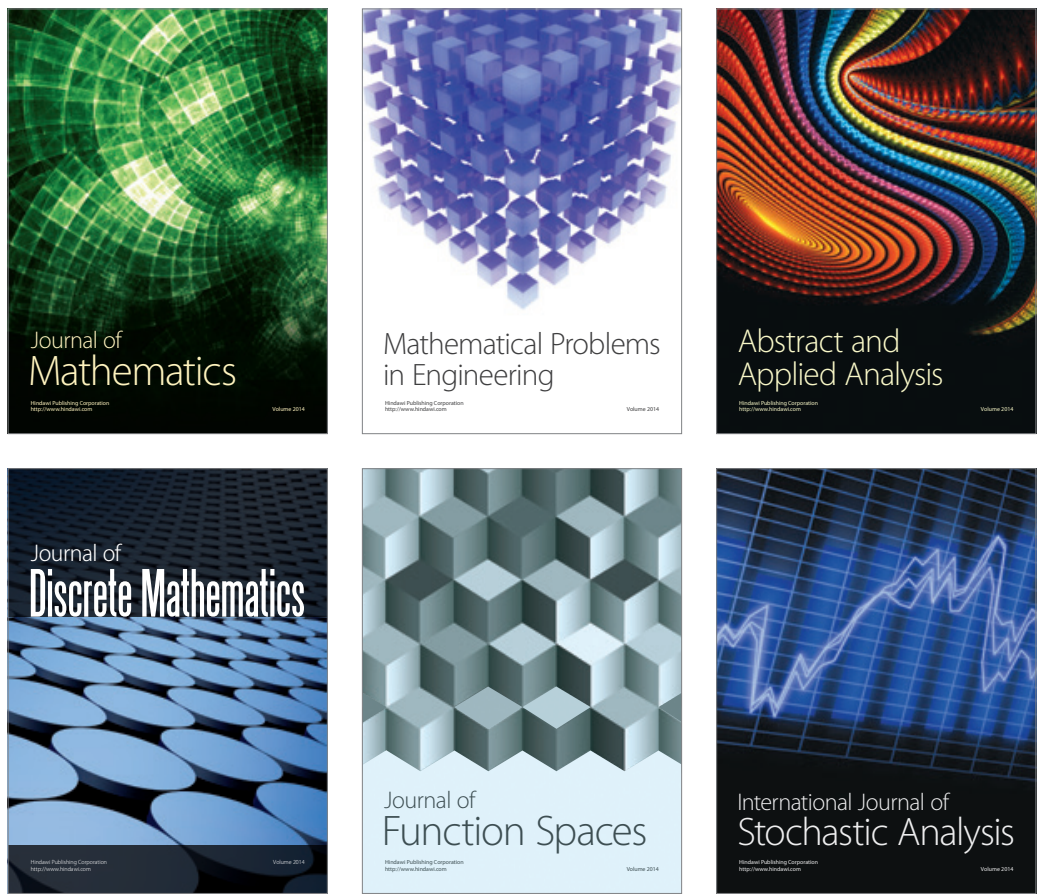

Journal of

Function Spaces

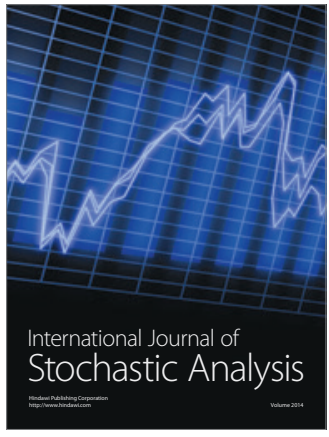

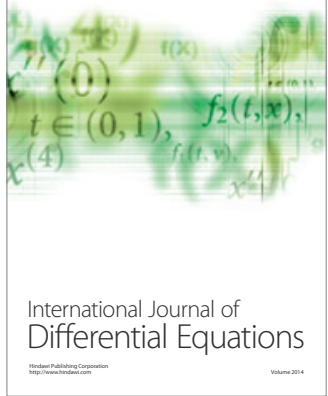
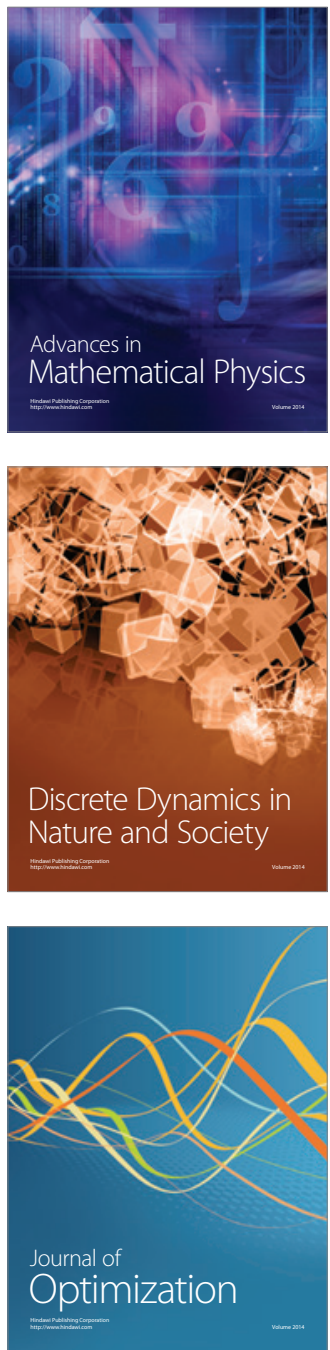